Article

\title{
Converting a Fixed-Wing Internal Combustion Engine RPAS into an Electric Lithium-Ion Battery-Driven RPAS
}

\author{
Fernando Isorna Llerena ${ }^{1, * \mathbb{C}}$, Álvaro Fernández Barranco ${ }^{1}$, José Antonio Bogeat ${ }^{1}$, \\ Francisca Segura ${ }^{2}$ and José Manuel Andújar ${ }^{2}$ (D) \\ 1 Instituto Nacional de Técnica Aeroespacial (INTA), Área de Energía. Ctra, Huelva-Matalascañas, km. 34, \\ 21130 Mazagón, Huelva, Spain; alvar0.gate@gmail.com (Á.F.B.); bogeatspja@inta.es (J.A.B.) \\ 2 Departamento de Ingeniería Electrónica, Universidad de Huelva, de Sistemas Informáticos y Automática, \\ 21007 Huelva, Spain; francisca.segura@diesia.uhu.es (F.S.); andujar@diesia.uhu.es (J.M.A.) \\ * Correspondence: isornaf@inta.es; Tel.: +34-959208847
}

Received: 8 January 2020; Accepted: 20 February 2020; Published: 25 February 2020

check for updates

Featured Application: The main application was to give a second life to an obsolete and declassified type of RPAS (remotely piloted aircraft system) for use in monitoring key parameters, in the cultivation of the olive tree and in other types of cultivation that occupy large areas of land. Similarly, it can be used to track and monitor endangered animal species. INTA (National Institute for Aerospace Applications) is located on the grounds of the Doñana National Park, where the Iberian lynx lives, one of the most threatened felines in the world, taking advantage of some of the main advantages of this RPA (remotely piloted aircraft) like autonomy, efficiency, low-noise level, and non-polluting.

\begin{abstract}
It is well proved that remotely piloted aircraft systems (RPASs) are very useful systems for remote sensing in precision agricultural labors. INTA (National Institute for Aerospace Applications) and the University of Huelva are involved in Tecnolivo Project that proposes the development of a marketable and easy-to-use technological solution that allows integrated, ecological, and optimized management of the olive grove through non-invasive monitoring of key agronomic parameters using RPASs. The information collected by the RPAS in regards to the state of the vegetation, such as hydric stress levels, plague detection, or maturation of the fruit, are very interesting for farmers when it comes to make decisions about their crops. Current RPAS applications for precision agriculture are mainly developed for small- to medium-sized crops using rotary-wing RPASs with small range and endurance operation, leaving aside large-sized crops. This work shows the conversion of a fully declassified and obsolete fixed-wing internal combustion engine (ICE) remotely piloted aircraft (RPA), used as aerial target for military applications and in reconnaissance and surveillance missions at low cost, into an electric lithium polymer (LiPo) battery-driven RPA that will be used for precision agriculture in large-sized crop applications, as well as other applications for tracking and monitoring of endangered animal species in national parks. This RPA, being over twenty years old, has undergone a deep change. The applied methodology consisted of the design of a new propulsion system, based on an electric motor and batteries, maintaining the main airworthiness characteristics of the aircraft. Some other novelties achieved in this study were: (1) Change to a more efficient engine, less heavy and bulky, with a greater ratio of torque vs. size. Modernization of the fly control system and geolocation system. (2) Modification of the type and material of the propeller, reaching a higher performance. (3) Replacement of a polluting fuel, such as gasoline, with electricity from renewable sources. (4) Development of a new control software, etc. Preliminary results indicate that the endurance achieved with the new energy and propulsion systems and the payload weight available in the RPA meet the expectations of the use of this type of RPAS in the study of large areas of crops and surveillance.
\end{abstract}


Keywords: remotely piloted aircraft (RPA); remotely piloted aircraft system (RPAS); unmanned aerial system (UAS); unmanned aerial vehicle (UAV); battery; precision agriculture; crops; remote sensing

\section{Introduction}

An unmanned aerial system (UAS) or unmanned aerial vehicle (UAV) is defined as a powered aerial vehicle that does not carry a human operator, uses aerodynamic forces to provide vehicle lift, and can fly autonomously or be remotely piloted aircrafts. In this last case, they are also called a remotely piloted aerial system (RPAS) (i.e., aerial platform (RPA) plus control station for pilot and operator (if applicable) actions [1-3]). UASs and RPASs (usually the same denomination is employed, even in the everyday jargon they are called drones) are mostly associated with military, industry, and other specialized operations, but with recent developments in the area of sensors and information technology in the last two decades, the scope of drones has been widened to other areas like agriculture [4].

The technology of RPASs for areas such as precision agriculture is drawing increasing attention from different sectors interested in seeking real-time, high-quality, high-volume crop data to accelerate crop improvement through breeding and to optimize agronomic practices [5-19].

Traditional imagery, provided, for example, by RGB (read green blue) and/or NIR (near infared) sensors, has proven to be useful in many agroforestry applications. However, it lacks the spectral range and precision to profile materials and organisms that only hyperspectral sensors can provide. This kind of high-resolution spectroscopy was firstly used in satellites and later in manned aircraft, which are significantly expensive platforms and extremely restrictive due to availability limitations and/or complex logistics. More recently, UASs have emerged as a very popular and cost-effective remote sensing technology, composed of aerial platforms capable of carrying small-sized and lightweight sensors. Meanwhile, hyperspectral technology developments have been consistently resulting in smaller and lighter sensors that can currently be integrated in UASs for either scientific or commercial purposes. The hyperspectral sensors' ability for measuring hundreds of bands raises complexity when considering the sheer quantity of acquired data, whose usefulness depends on both calibration and corrective tasks occurring in pre- and post-flight stages [15].

Independent of the aerial platform, sensors play an important role in data acquisition. According to [20], in which an extensive work addressing hyperspectral technology can be found, there are four main techniques for acquiring measurable data from a given target: By hyperspectral imaging, multispectral imaging, spectroscopy, and RGB imagery. The most significant differences are synthetized in Table 1, which considers not only the comparison carried out by [20] but also the vision of Sellar and Boreman [21], who stated that imaging sensors for remote sensing can be divided into the method by which they achieve (1) spatial discrimination and (2) spectral discrimination.

Table 1. Differences between hyperspectral and multispectral imaging, spectroscopy, and RGB (read green blue) imagery. A classification based on a bullet rate (1-3) was used to quantify both the spectral and spatial information associated to each acquisition technique, in relative terms.

\begin{tabular}{ccc}
\hline & Spectral Information & Spatial Information \\
\hline Hyperspectral Imaging & $\bullet \bullet \bullet$ & $\bullet \bullet \bullet$ \\
Multispectral Imaging & $\bullet \bullet$ \\
Spectroscopy & $\bullet \bullet$ & $\bullet \bullet$ \\
RGB Imagery & $\bullet$ & $\bullet \bullet$ \\
\hline
\end{tabular}

Regarding the aerial platform, different types of RPAS models which have been used in the last two decades are shown in Table 2 [22]. 
Table 2. Different types of RPAS (remotely piloted aircraft system) models developed in past studies for precision agriculture.

\begin{tabular}{cc}
\hline Type & Reference \\
\hline Fixed-wing & {$[23-26]$} \\
Single-rotor helicopter & {$[27-31]$} \\
Quad copter & {$[32-36]$} \\
Hexa copter & {$[30,37-40]$} \\
Octo copter & {$[41-45]$} \\
\hline
\end{tabular}

Fixed-wing (Figure 1a) RPASs are entirely different in their design compared to multi rotors, and aerodynamic shape of two wings provides an easy glide for RPAs. The single-rotor helicopter (Figure 1b) is a model with just one big-sized rotor on top and one small-sized rotor on the tail of the RPA. Quad copter (Figure 1c), hexa copter (Figure 1d), and octo copters (Figure 1e) are multi-rotors which are lifted and propelled by four, six, and eight rotors, respectively.

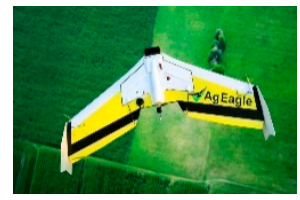

(a)

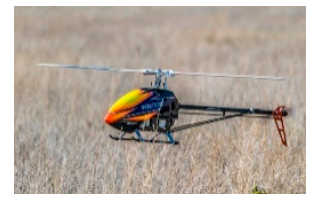

(b)

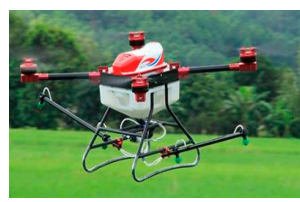

(c)

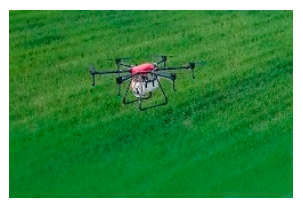

(d)

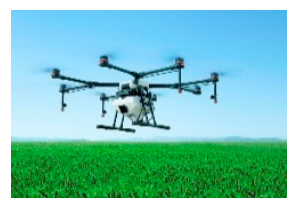

(e)

Figure 1. RPAS (remotely piloted aircraft system) types: Fixed-wing (a). Single-rotor (b). Quad Copter (c). Hexa Copter (d). Octo Copter (e).

Current RPAs applications for precision agriculture are mainly developed for small- to medium-sized crops, using rotary-wing RPASs with small range and endurance operation, leaving aside large-sized crops, but farmers with a lot of hectares of land find it difficult to reach each corner of field for inspection each time. The fixed-wing RPAS does this task without any hiccup, as farmers can do regular air monitoring of fields to know the status of their crops at regular intervals of time. Table 3 compares the main features of fixed-wing vs. rotary-wing UAVs.

Table 3. Advantages and disadvantages of fixed- and rotary-wing aircraft.

\begin{tabular}{cccc}
\hline \multicolumn{2}{c}{ Fixed-Wing } & \multicolumn{2}{c}{ Rotary-Wing } \\
\hline Advantages & Disadvantages & Advantages & Disadvantages \\
\hline Autonomy & Non-stationary flight & Stationary flight & Autonomy \\
Range & Difficult maneuverability & Stability & Consumption \\
Altitude & Non-modifiable designs & Control & \\
Speed & & Maneuverability & \\
Consumption & & Size & \\
\hline
\end{tabular}

In Table 4, an evaluation was done to compare electric vs. internal combustion engine (ICE) engines in both fixed-wing and rotary-wing UAVs regarding some technical characteristics, like payload, wind resistance, autonomy, and landing distance. It can be seen that fixed-wing electric UAVs are those that present more equitable flying parameters. 
Table 4. Evaluation of some UAV (unmanned aerial vehicle) platforms, according to the literature [46-48] and the authors' experience. The evaluation is from 1 (low) to 5 (high).

\begin{tabular}{ccccc}
\hline & & Fixed-wing & \multicolumn{2}{c}{ Rotary-wing } \\
\hline & Electric & ICE (Internal Combustion Engine) Engine & Electric & ICE Engine \\
\hline Payload & 3 & 4 & 2 & 4 \\
Wind resistance & 2 & 3 & 2 & 4 \\
Minimum speed & 2 & 2 & 4 & 4 \\
Flying autonomy & 3 & 5 & 2 & 4 \\
Portability & 2 & 2 & 3 & 3 \\
Landing distance & 3 & 2 & 4 & 4 \\
\hline
\end{tabular}

Concerning the power supply system of UAVs, electric UAVs are characterized by great advantages such as reliability, efficiency, low-noise, reduction of heat losses, as well as getting an energy supply free of polluting emissions [49]. However, the energy management of these UAVs requires more advanced control, which also takes into account many storage and power supply options [50].

Although it is usual to find that electric UAVs make use of batteries, among which many types have to be differentiated, these have, in general, low-energy density and very large charging times. However, batteries provide great autonomy and reliability of a technology with much development today. Within the different types of batteries, it is not only necessary to assess their electrical characteristics, but also their weight, since this critically influences the energy consumption of the UAV, and; therefore, its autonomy. Looking at the Table 5 [51], the energy comparison of the four main types of batteries used in electric UAVs today can be seen. It is found that lithium polymer (LiPo) batteries have a very large specific power, which is the reason why they are used in $90 \%$ of UAVs of micro-aerial vehicles. LiPo batteries also have a good relationship of specific energy and energy density, although it can be found in higher values in Li-S (lithium-sulfur) batteries, at the expense of an obvious lower specific power.

Table 5. Batteries electric characteristics comparison.

\begin{tabular}{ccccc}
\hline & $\begin{array}{c}\text { Ni-Cd } \\
\text { (Nickel-Cadmium) }\end{array}$ & $\begin{array}{c}\text { Ni-Mh (Nickel } \\
\text { Metal Hydride) }\end{array}$ & $\begin{array}{c}\text { LiPo (Lithium } \\
\text { Polymer) }\end{array}$ & $\begin{array}{c}\text { Li-S } \\
\text { (Lithium-Sulphur) }\end{array}$ \\
\hline Specific energy (Wh/kg) & 40 & 80 & 180 & 350 \\
Energy density (Wh/L) & 100 & 300 & 300 & 350 \\
Specific power (W/kg) & 300 & 900 & 2800 & 600 \\
\hline
\end{tabular}

In addition to different types of batteries, alternatives for recharging can also be considered. Swapping involves exchanging a battery for another already charged, which avoids great complexity in energy management but reduces the necessary size of the batteries [52]. With the laser-beam charging base, an optimal receiver transforms the received light into electricity, thereby avoiding the risks associated with landings, at the cost of reducing the useful height where it can be operated, as well as the search for a location without obstructions for an effective recharge [53]. Tethered UAVs are the safest form of energy transfer, when performed directly, although they reduce the area of operation in a limited way [54].

When a more balanced operation is wanted, supercapacitors can be used. These allow a very high-energy density with a rapid response dynamic, which facilitates the start-up of the equipment, as well as maneuvers that require a greater instantaneous energy supply. It is also possible to make use of fuel cells, where hydrogen as an energy vector provides electricity [55], with great advantages in terms of weight and equipment maintenance, although with a slow dynamic. Additionally, fixed-wing UAVs have the possibility to carry solar cells and use solar energy, so fuel consumption can be reduced [56,57].

In Figure 2, it can be seen how each technology has very differentiating characteristics in terms of its energy supply capacity. That is why more and more electric UAVs makes use of hybridization 
among the different technologies [58], taking the benefits of the advantages of each one of them, and adapting to the application for which the electric UAV is designed for [59].

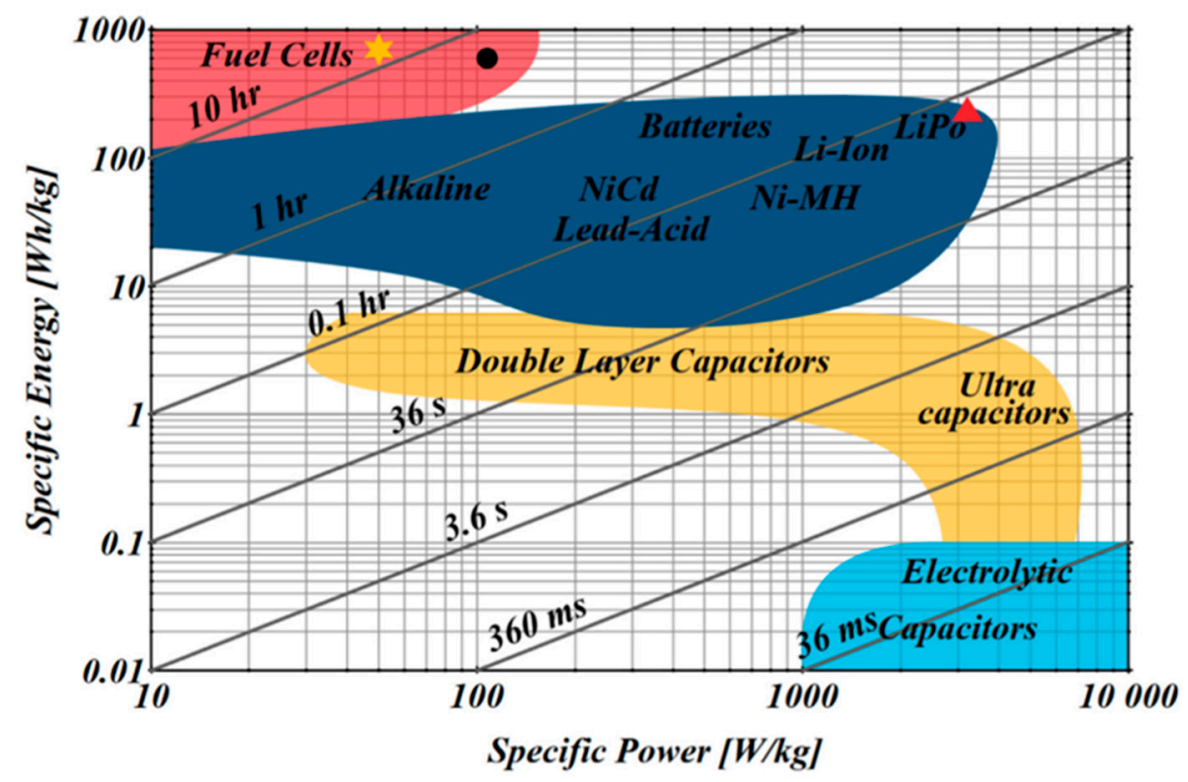

Figure 2. Specific energy/power comparison among different energy sources.

The hybrid combination of different types of energy storage also requires the implementation of larger control systems [60], so that they must reach a balance between energy management alternatives and the size required for computer control equipment, together with the different sensors and actuators that make up the plant balance [61].

After this review of the state-of-the-art of electric UAVs, it is realized that one of the solutions, that the literature shows as the most promising in terms of flight autonomy, is the use of hydrogen and fuel cells in electric RPASs [62-65]. As a first step for this ambitious ultimate goal, a fixed-wing electric RPA was developed.

This work shows how a fixed-wing RPA with an internal combustion engine, used as a target for military applications, was deeply modified in order to transform it into an electric RPA, equipped with a pack of LiPo batteries with the proper battery management system (BMS) and an electric engine with suitable controller. A propeller was also changed, but the main airworthiness characteristics of the RPA were maintained.

Among the main advantages of electric engine is that they are of universal use, widely understood, simple in concept and operation, large efficiency, low cost due to economies of scale, and very low-noise level [66].

\section{TecnOlivo Project}

TecnOlivo pursues modernizing a traditional agricultural sector such as olive cultivation, by creating a pioneering technological device that opens up new business opportunities, and places the olive production industry of Huelva and that of the southeast of Portugal at the forefront of international innovation and, by extension, the rest of Andalusia, Spain, and Portugal.

With 2.5 million euros of budget, co-financed with FEDER Funds and submitted to the first call of the INTERREG V-A Spain-Portugal Programme (POCTEP 2014-2020), the project targeted the development of a marketable technological solution (TecnOlivo) to be easily-used by farmers, and which allows the integral, ecological, and optimized management of the olive grove by monitoring non-invasive agronomic parameters of interest to partner olive growers. With TecnOlivo, partners sought to improve the sustainability of olive cultivation, by favoring an optimal use of resources. 
TecnOlivo represented a holistic solution to traditional olive farming in which an unmanned aerial vehicle captured georeferenced crop information through cameras or other sensors, and integrated the data collection, transmission, analysis, processing, visualization, action guidelines, and "learning processes," in an easy and ergonomic way for the farmer. It was supported by a network of low-cost ground sensors, which will constitute a relevant intelligent tool for olive farmers, such as those ancient farming tools and farm tractors were in their days. Thus, TecnOlivo will allowed olive growers to know, in real-time and on-the-spot, information on key parameters such as the hydric status and nutrients of the groves, what extent treatments were needed, and in what areas of the orchards.

During the development of the project Tecnolivo [67-70], different types of rotary-wing RPASs were used, but when the extensions of the study area were very large, an RPA with greater autonomy was missing.

The TecnOlivo project proposed a methodology for plant detection, geolocation, and counting in olive orchards, based on aerial imagery and image processing and analysis. To that end, an RPAS equipped with a multispectral camera was used to carry out image acquisition. The captured multispectral images were processed in order to yield a DSM (digital surface model). This data structure was subsequently transformed by means of mathematical morphology, aiming to individually segment the olive trees appearing in the images from the ground.

Aerial imaging was conducted using a DJITM Matrice 100 RPAS (SZ DJITM Technology Co., Ltd., Shenzhen, Guangdong, China). This aircraft is propelled by four rotors (quadcopter), enabling its vertical take-off and landing.

Images were taken with the multispectral camera MicaSense RedEdge-MTM (MicaSense, Inc., distributed by ACRE surveying solutions, Spain), installed on the RPAS. This sensing device was capable of capturing information in five different spectral bands within the visible and the infrared spectrum.

The main problem was that the quadcopter batteries had to be changed every 15 or $20 \mathrm{~min}$, making the data collection missions very short. For this reason, the goal of this paper is to propose a methodology to transform an ICE RPA into an electric RPA with the aim that the developed aerial platform takes advantages from both ICE and electric technology.

Preliminary results indicate that the endurance achieved with the new energy and propulsion systems and the payload weight available in the RPA meet the expectations of the use of this type of aerial platform in the study of large areas of crops. The autonomy achieved by the electric RPA is almost $50 \%$ more than the same model with internal combustion engine. If it is compared with the commercial UAV (multicopters) models currently used in the TecnOlivo project, the advantage in terms of flight autonomy and surface to be treated is enormous.

Because of this transformation, additional novelties were achieved: (1) A more efficient engine, less heavy and bulky; (2) a greater ratio of torque vs. size; (3) the development of a dedicated software in order to monitor and control the parameters related to the new power system; (4) the design of a new and less-consuming telemetry module able to establish communication between the ground control station (GCS) and the RPA BMS and motor controller; and (5) the design and 3D printing of parts such as battery case, telemetry module chassis, propeller cone, and motor controller housing.

This work is divided into the following sections. After this introduction, Section 2 describes in detail the materials and method used. Afterwards, the tests performed are presented in Section 3, including the results obtained with the modified electric RPA. Lastly, discussion and conclusions are explained and future works are depicted in Sections 4 and 5, respectively.

\section{Materials and Methods}

\subsection{Description of Original RPA. ALO project}

The selected RPA for this work was chosen from the Project ALO (in Spanish, Avión Ligero de Observación-lightweight reconnaissance plane) that is an RPA developed by INTA (in Spanish, Instituto Nacional de Técnica Aeroespacial-National Institute of Aerospace Technology) which 
can provide real-time reconnaissance, surveillance, and target acquisition information by means of interchangeable, steerable TV and FLIR (forward-looking infrared sensor) cameras. The images can be sent in real-time to the ground control station (GCS) where image processing capabilities are provided.

In a typical mission performed by ALO, the RPA is transported to the launching site in the transportation vehicle that also plays the role of ground control station, Figure 3. The whole RPAS is transported on a single vehicle (Unimog size), which provides great mobility and transport capabilities, allowing missions from non-prepared locations. Assembly and installation of the RPA can be accomplished in less than $30 \mathrm{~min}$ without the use of special tooling.

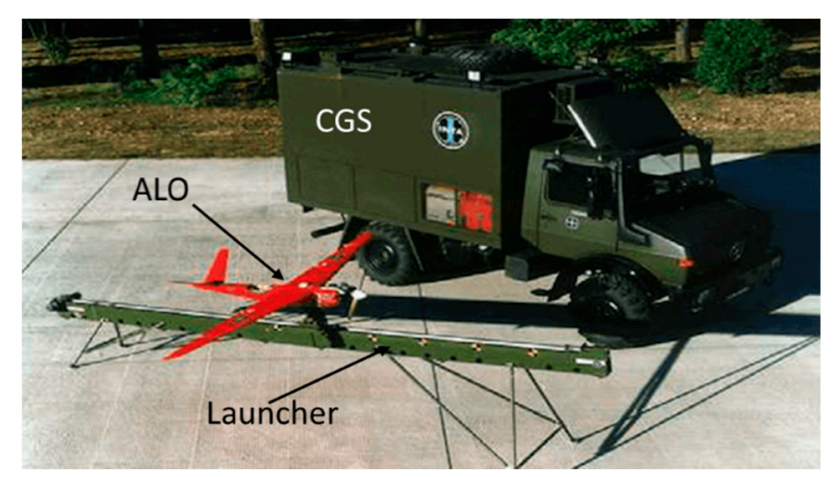

Figure 3. Completed ALO (Avión Ligero Observación) system: Control ground station, rubber bungee launcher, and aerial aircraft.

After loading the waypoints on the on-board computer, the UAV is launched from a hydraulic or pneumatic launcher. The RPA will fly the programmed mission over the surveillance area transmitting, in real-time, the images captured by the camera and relevant telemetry data, such as, position of the RPA, speed, fuel consumption, revolutions per minute (rpm) of the RPA engine, or altitude. In case of detecting any possible target, activity, or area of interest, the pilot located at the GCS can take manual control of the RPA flying around the selected point.

When the mission finishes, or whenever decided by the pilot, the RPA can return autonomously to the launching site and the recovery will be performed by means of a parachute. Furthermore, for mission evaluation, the whole mission is recorded and can be replayed on a video monitor where the all the main flight parameters are displayed.

\section{ALO RPAS Description}

The ALO RPA could perform reconnaissance, surveillance, and target acquisition missions at a distance of up to $50 \mathrm{~km}$ from the GCS for a maximum of $60 \mathrm{~min}$. Nominal observation speed of the $\mathrm{RPA}$ is $70 \mathrm{~km} / \mathrm{h}$.

To carry out an operation, the RPAS was divided in the Air Segment (RPA + payload + spare parts) and the Ground Segment (GCS + transportation vehicle + launcher + tools and spare parts). Specifically:

(a) Air Segment:

- $\quad$ RPA

- $\quad$ Steerable TV and FLIR cameras

- $\quad$ Spare parts to guarantee 1 week of deployment with 3 missions per day

(b) Ground Segment:

- $\quad$ Transportation vehicle

$-\quad$ GCS 
- $\quad$ Hydraulic or pneumatic launcher

- $\quad$ Maintenance tools

- Spare parts

The specific design features of the engine and aerial platform provides the RPA with very high climbing rates and a wide range of flight speeds: The UAV can reach the area of interest at a high speed and then decrease the speed down to facilitate recognition and identification of targets. Figure 4 shows an ALO RPA in the launching pad and Table 6 states the main features of the RPA regarding dimensions, weights, and performance values.

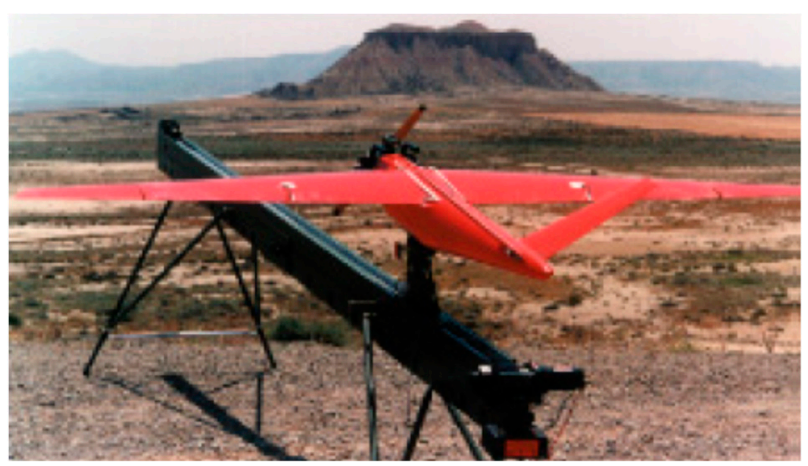

a)

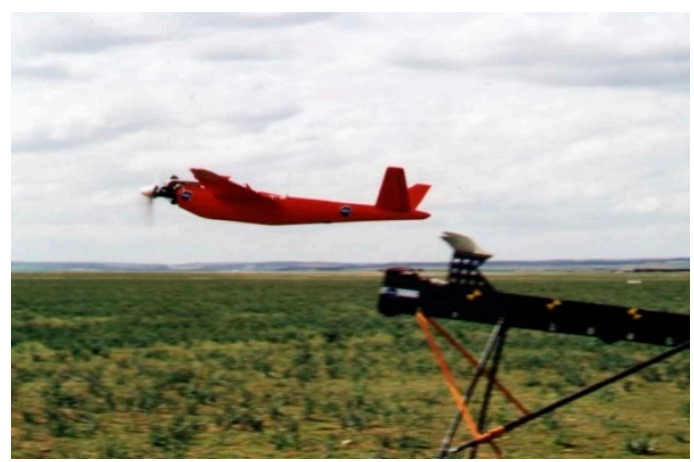

b)

Figure 4. (a) ALO Avión Ligero Observación) RPA in the launching pad (b) ALO taking off.

Table 6. ALO RPA technical characteristics.

\begin{tabular}{cc}
\hline Characteristics & Value \\
\hline Wingspan & $3.03 \mathrm{~m}$ \\
Length & $1.8 \mathrm{~m}$ \\
MTOW (Max. Take-Off Weight) & $25 \mathrm{~kg}$ \\
Wing Area & $0.85 \mathrm{~m}^{2}$ \\
Max. Payload & $7.5 \mathrm{~kg}$ \\
Endurance & $1 \mathrm{~h}$ \\
Speeds & $50-225 \mathrm{~km} / \mathrm{h}$ \\
ROC (Rate of Climb) & $6 \mathrm{~m} / \mathrm{s}$ \\
Range & $50 \mathrm{~km}$ \\
\hline
\end{tabular}

To understand the RPA architecture, the main parts are:

(1) Airframe: The RPA is a conventional V tail fixed-wing aircraft made of reinforced fiber glass. The airframe can be easily disassembled in parts: fuselage, tail cone, and wing. The tips of the wing can also be disassembled. This modularity improves maintainability and allows and easy transportation of the RPA.

The main components of the airframe are:

- $\quad$ Fuselage: Made of epoxy resin and fiberglass layers. The fuselage is a non-divided compartment without bulkheads or internal structural elements. This feature gives ALO the possibility to accommodate a wide variety of payloads and avionics equipment.

- $\quad$ Tail cone: Fiberglass layers enclosing a core of Rohacell@. Very simple union with the fuselage.

- Wing: The wing is a sandwich structure made of fiberglass layers and Nomex(C). As in the fuselage, no internal ribs or structural elements are provided. The volume enclosed by the fuselage is in contact with the volume enclosed by the wing, significantly increasing 
the available volume for payload of fuel. The wing tips can be disassembled in order to facilitate the transport.

- $\quad$ Control surfaces: Fiberglass layers enclosing a core of Rohacell@ C. The control surfaces are deflected by commercial "off-the-shelf" brushless servo motors.

(2) Propulsion system: The power plant consists of a two-cylinder two stroke reciprocating engine providing 6.8 HP (horse power). The engine drives a fixed-pitch two-blade propeller. The propulsion system is located at the front of the RPA and is joined to the bulkhead by means of four silent blocks. The fuel tank is located in the wing. The carburetor has an integrated fuel pump. The fuel used is an oil: gasoline mixture 1:50 [71].

(3) Electric Power System: The main electric power source are packs of Ni-Cd batteries that provide the required power for a period of $60 \mathrm{~min}$, just for auxiliary electrical loads.

(4) Navigation Guidance and Flight Control Systems (NGFCSs): The NGFCS is an extensively-proven "off-the-shelf" package including a GPS receiver that allows autonomous flights, an autopilot for stabilization, and an azimuth control unit to fly the RPA following the different commanded azimuth directions. The NGFCS allows different flight modes:

- $\quad$ Autonomous: Follow the waypoints loaded in the mission planning.

- Semi-automatic: The RPA is controlled by the pilot but without direct control on all control surfaces.

- $\quad$ Manual: The pilot has full control of the RPA.

- $\quad$ Failsafe: In case of loss of up-link the RPA will enter in Failsafe mode. In this mode the RPA adopts a predefined configuration which was selected by the pilot/operator during the pre-flight phase.

\subsection{Modifications Performed to Original ALO RPA}

An ALO block diagram of the internal combustion engine version can be seen in Scheme 1.

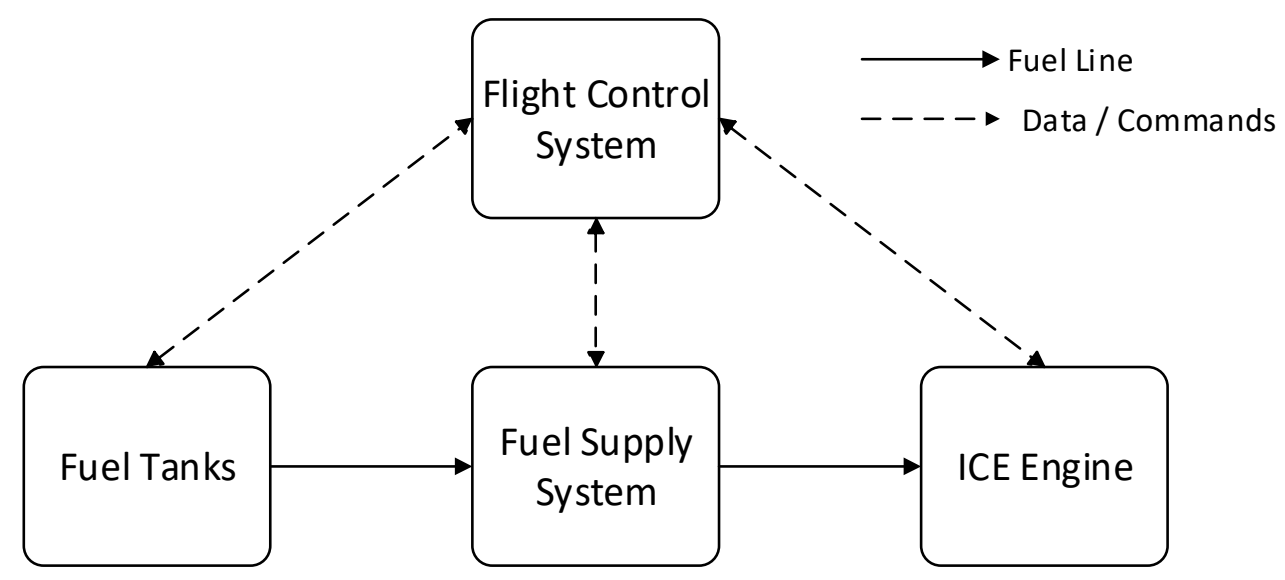

Scheme 1. ICE ALO Block Diagram. Where ICE is internal combustion engine.

With the aim to achieve a 100\% electric RPA, the first task performed in ALO RPA was to remove all the components related to the ICE propulsion system, Scheme 2:

- ICE engine.

- Harnesses.

- Fuel tanks (in wing).

- Fuel supply system.

And the new power plant of the ALO consists of four fundamental elements: 
- Electric engine.

- $\quad$ Electronic Speed Controller (ESC).

- Battery and BMS (Battery management system).

- Propeller.

- Telemetry module.

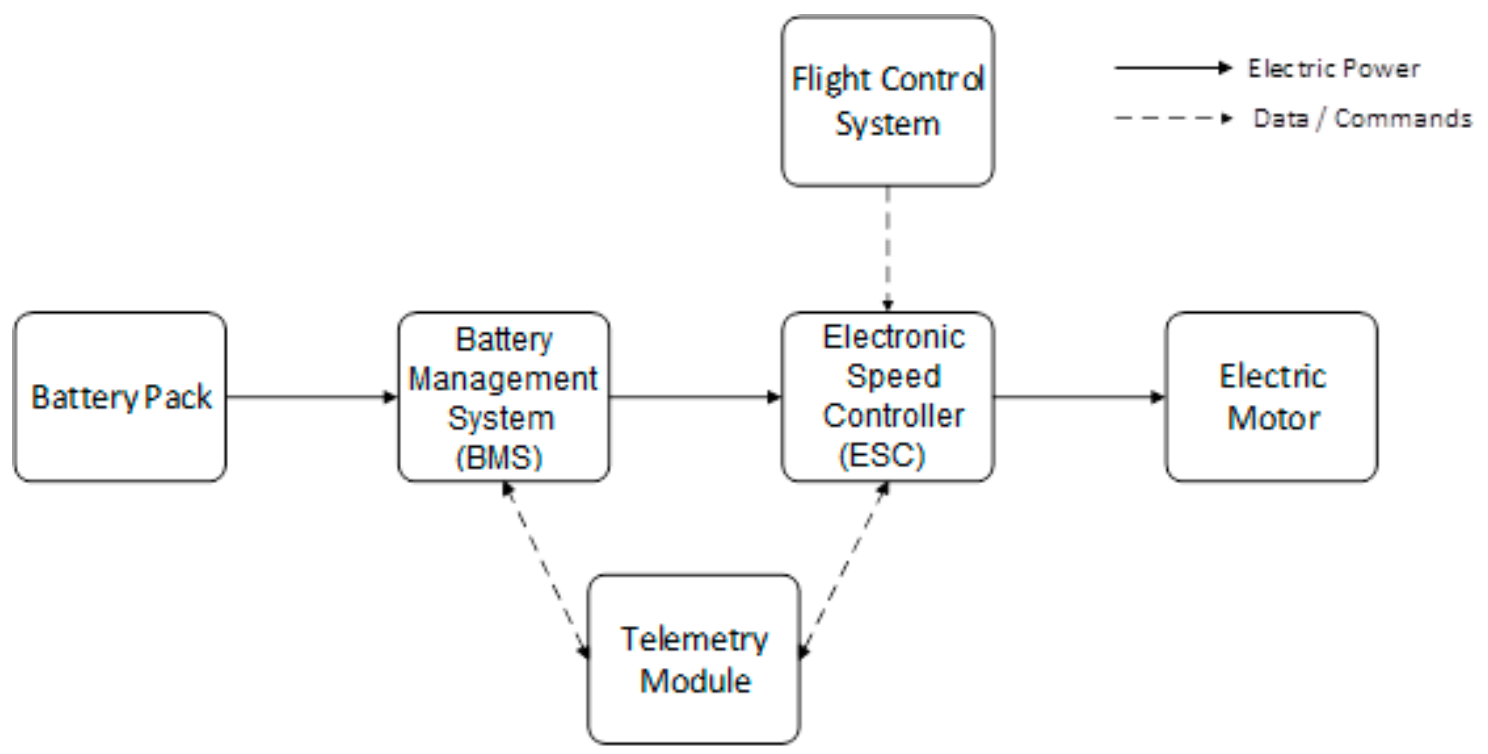

Scheme 2. Electric ALO Block Diagram. Where BMS is battery management system) and ESC is Electronic Speed Controller.

\subsubsection{Electric Engine}

ALO RPA originally had a two-cylinder two-stroke reciprocating engine (see Figure 5). The new configuration, with an electric engine, needs to achieve at least the same power. The chosen electric engine for the retrofitting platform is the DC electric engine Plettenberg $($ C Predator 37-6 brushless (BLDC) outrunner type, manufactured by Plettenberg(C) Elektromotoren $\mathrm{GmbH}$ and Co., Baunatal, Germany. It weighs only $1.9 \mathrm{~kg}$, has a maximum power of $12 \mathrm{~kW}$, allows a maximum current intensity of $308 \mathrm{~A}$, and can work with 12-14-cell (3 V each) battery packs. The manufacturer also declares an efficiency of $87 \%$. The main characteristics of the electric engine are shown in Table 7.

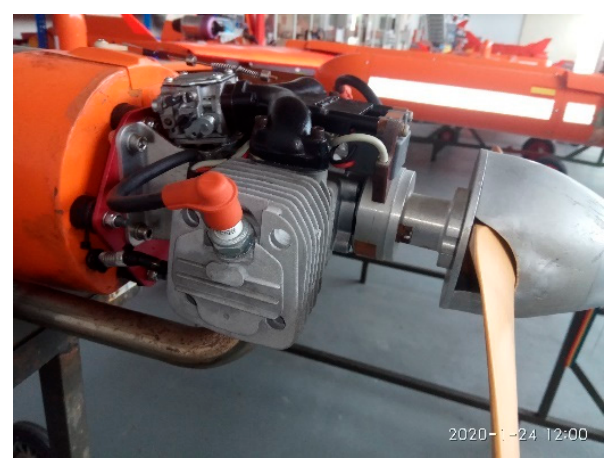

Figure 5. Original ALO internal combustion engine with a two-blade wooden propeller. 
Table 7. Electric engine characteristics.

\begin{tabular}{ccc}
\hline Voltage (V) & $\mathbf{1 4} \times \mathbf{3 . 0 ~ V}$ & $\mathbf{4 2 ~ V}$ \\
\hline Maximum current (I) & & $308 \mathrm{~A}$ \\
Motor Efficiency ( $\mathrm{\eta})$ & $87 \%$ \\
Maximum power: & $\mathrm{P}=\mathrm{V} \times \mathrm{I} \times \mathrm{\eta}$ & $11.25 \mathrm{~kW}$ \\
\hline
\end{tabular}

As shown, the engine has more than enough power to propel the RPA, even if it finally had an increase in total weight [72].

The main feature of BLDC engines is the absence of brushes on switching for the transfer of power, since brushes produce friction, decrease performance, generate heat, are noisy, require periodic replacement, and; therefore, require greater maintenance [73]. Some of the advantages of the BLDC motors in regards to conventional DC motors are:

- Best relationship speed torque engine.

- Greater dynamic response.

- Greater efficiency.

- Greater life time.

- $\quad$ Lower noise.

- Greater range of speed.

In addition, the torque: size ratio is much greater, thus are very useful in work environments with reduced space. These motors develop their maximum torque from $0 \mathrm{rpm}$, so reduction gear is usually not needed, and it can be attached directly to a propeller. It has permanent magnets installed in the outer shell of the engine and the winding is attached to the shaft. These motors require ESC, which transform DC battery power into a three-phase alternating current and feed it to the windings in a certain sequence depending on the position of the rotor.

\subsubsection{Electronic Speed Controller}

The used ESC for this motor is the HBC series V7 25063-3 by MGM-ComPro@. It is a controller for low-power programmable brushless electric motors.

This motor speed controller provides high-quality and smooth motor control for the RPA and gives the possibility for safe disconnection of the battery when running the motor (emergency STOP).

ESC uses the best available power MOSFETs (metal oxide semiconductor field effect transistor) or IGBT (Insulated gate bipolar transistor) modules for higher voltage and synchronous pulse-width modulation (PWM) and very powerful 32-bit ARMC microcontrollers to achieve very high efficiency. Software and firmware updates can be carried out by connecting to the internet at any time. Thanks to this, ESC is easily accessible and customer-specific modifications and adjustments can be performed. Its basic features are:

- Working range: from low voltage up to $63 \mathrm{~V}$, up to $250 \mathrm{~A}$ continuous power.

- Small dimension and weight.

- Very clear and easy parameter settings by PC.

- $\quad$ Data transfer to PC (or other equipment) and displaying in real-time (monitoring).

- Synchronous rectification, very high efficiency $98 \%-99 \%$.

- $\quad$ Motor PWM in range 8-32 kHz.

- Suitable for motors without pole limiting.

- Sensor motors as well as sensorless motors are supported.

- Support regenerative braking and battery charging under braking.

- Support many working modes (PWM, constant rpm, constant torque/car mode, boat mode, plain mode). 
- Electronic reversing.

- Support measuring (monitoring) of each battery cell.

- Support any type of battery: NiCd, NiMH, Lipo, Li-Ion, LiFePo4, Pb, etc.

- Monitors controller temperature, motor temperature, and battery temperature.

With respect to the possibility of parameters setting, it is necessary to have a PC running the Microsoft operating system and a USB cable. The PC must have the "Controller 2" software installed, see Figure 6.

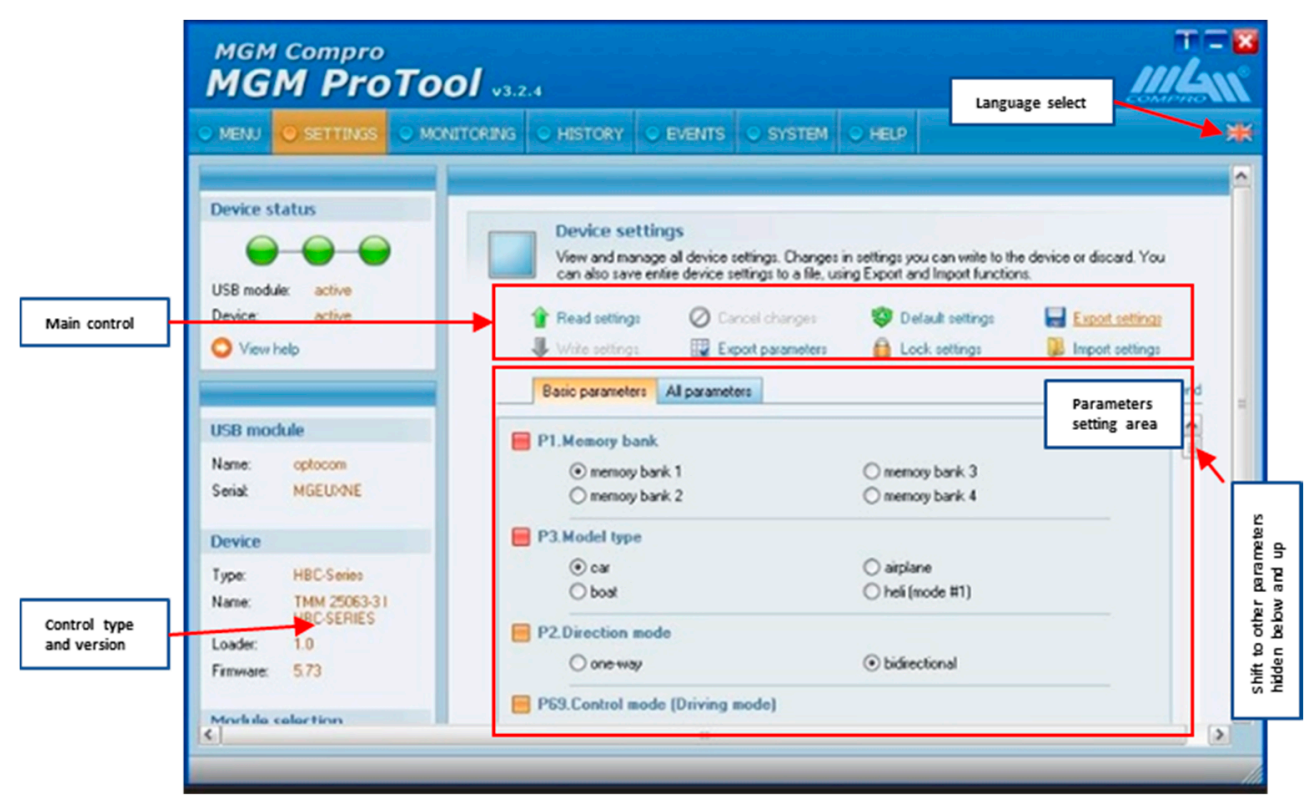

Figure 6. Controller 2 software screen with description and the possible values for all the parameters.

By default, settings of parameters in "Controller 2" software represents only average values. These values are usable as "starting values" for starting the system testing. In this case, it was necessary to adapt many parameters for the best behavior of the ESC with the available hardware. The description and the possible values for all the parameters are available in the operating manual of the controller [74].

\subsubsection{New Electronic Power System}

\section{Battery and BMS}

Taking into account a typical mission power needs, and the expressions for energetic content and capacity of a battery [75], the final battery pack was composed by 28 commercial 16,000 mAh 15 C 3.7 V Lithium Polymer battery cells [76] with 14-series and 2-parallel configuration (14s2p), achieving a final pack with $32,000 \mathrm{mAh}$ theoretical capacity and $58.8 \mathrm{~V}[77,78]$.

For the selected electric motor, the different types of commercial batteries available were taken into account: Acid lead, NiMH, NiCd, LiPo, and LiFePO4, although new materials for batteries in aerospace and aeronautical applications will be available in the coming years [79-81]. However, with the actual state of technology and market prices, it was concluded that the best battery to be used in the electric ALO is the lithium polymer ( $\mathrm{LiPo}$ ) battery. It is the one with the highest specific energy, despite being the most fragile. Its main advantages are reflected below:

(a) High voltage per cell. In this case, the nominal voltage of each cell is $3.7 \mathrm{~V}$, and can reach a maximum value of $4.2 \mathrm{~V}$.

(b) High specific energy, around $200 \mathrm{Wh} / \mathrm{kg}$.

(c) Low weight. 
(d) High power density.

(e) Fast charge.

(f) Long life, which translates into economic savings.

(g) Passivation phenomenon: it consists in the formation of a lithium chloride film that forms on the surface of the anode and prevents its self-discharge. This is beneficial if the battery is not used for a long period of time, as it prevents it from discharging.

In contrast, some disadvantages are:

(a) Degradation at temperatures higher than $60^{\circ} \mathrm{C}$.

(b) Degradation if discharged below its minimum voltage, $3 \mathrm{~V}$.

(c) Because of the two previous limitations, it is essential to use a BMS (battery management system), which controls the operating range of the batteries, and is able to disconnect them if their operation exceeds the permitted thresholds.

The amount of energy, $E$, stored in the battery is expressed in watt.hours (Wh) and is represented by Equation (1):

$$
E=\int_{0}^{t} U(t) * I(t) d t
$$

Usually when calculating this value, a constant current discharge mode can be used in such a way that the only variable in the equation is the voltage. The specific energy is measured in watt-hours per $\mathrm{kg}(\mathrm{Wh} / \mathrm{kg})$ and it should be as high as possible since in mobile applications the weight is a key factor. This parameter will then be decisive when deciding what type of battery will be used in the ALO, which will be introduced later.

The battery capacity, $C_{A h}$, is defined internationally as the electric charge, in amp hour (Ah) units, which can be extracted from a battery. When a battery is discharged at a non-constant current, the capacity is given by Equation (2):

$$
C_{A h}=\int_{0}^{t} I(t) d t
$$

The capacity depends on discharge parameters, as well as: (1) The discharge current, (2) limits imposed by the voltage (cut-off voltage, final discharge voltage, initial voltage, state of charge, etc.), and (3) operating temperature.

When reaching the necessary voltage or achieving the desired capacity, the cells must be connected in series, parallel, or a combination of both. The serial connection consists of connecting the positive and negative terminals of two cells in such a way that the voltage increases, although the capacity remains the same. The parallel connection consists of connecting the terminals of the same sign (positive with positive and negative with negative) in such a way that the total voltage remains the same, but the capacity doubles. When selecting the configuration to be used in the application, it is necessary to take into account the voltage first and finally the capacity. In this case, the named 14-series and 2-parallel (14s2p).

The cells were packed in a custom 3D printed case (Figure 7) with all the couplings and fasteners secured in the main bay of the RPA. It also had vertical openings for better temperature management. 


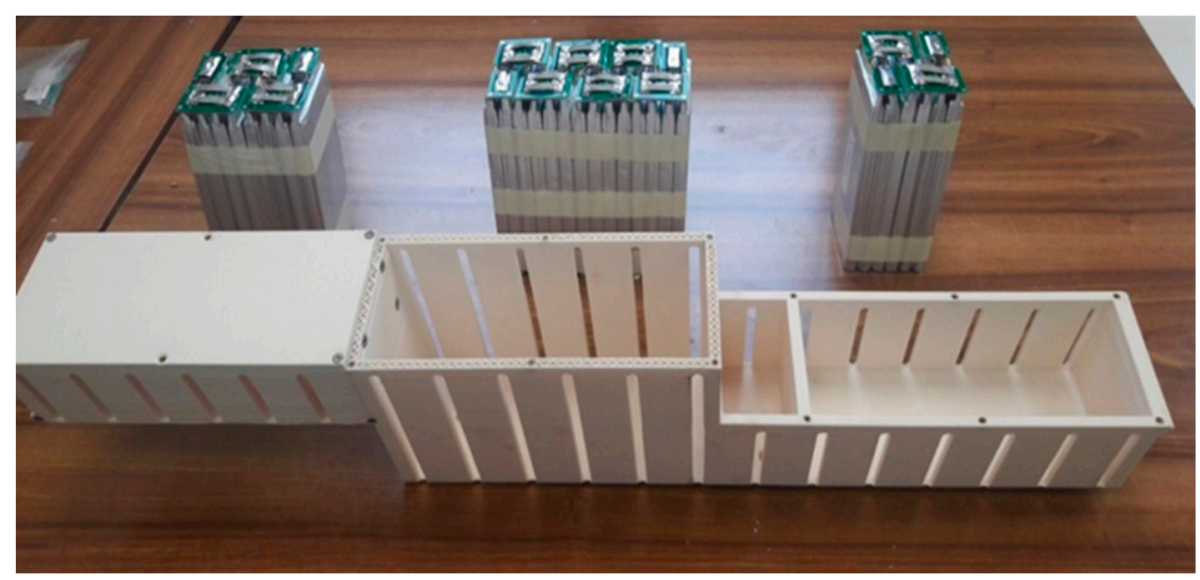

a)

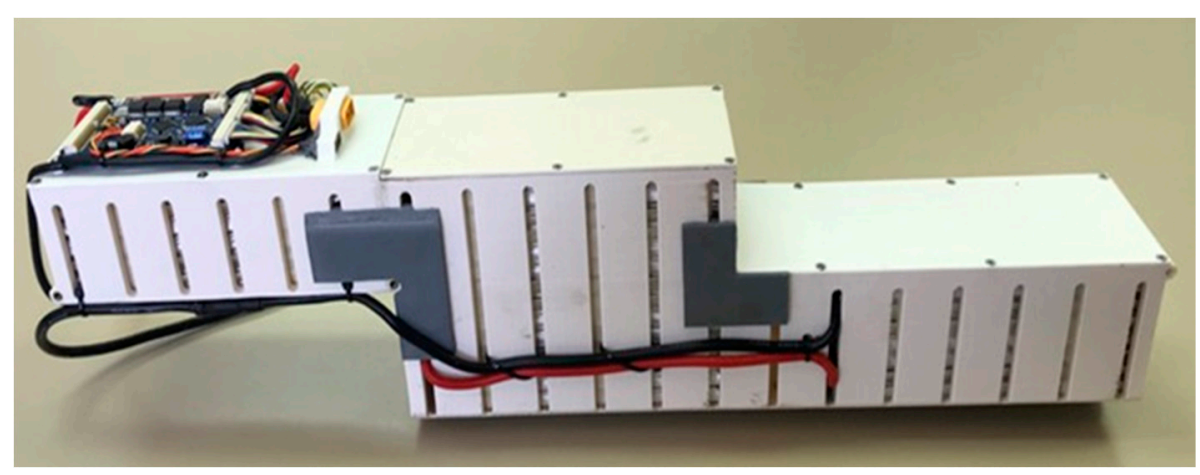

b)

Figure 7. (a) 3D printed batteries case with 3 blocks duly welded together (b) batteries connected inside the case.

The BMS is the Tiny BMS s516 150 A model from the company Energus Power Solutions@, Vilnius, Lithuania. It is widely used in the battery pack charging process, allowing the balance of the different cells. Cell balancing starts when the difference between any of the 14 series cells is bigger than $30 \mathrm{mV}$. BMS also monitors voltage cell levels and two temperature sensors distributed in the battery pack.

The BMS can be configured using the Battery Insider Windows application and a USB cable connected to the BMS communication interface connector. Alternatively, all the BMS configuration can be done using UART (Universal asynchronous receiver-transmitter), MODBUS or CAN (controller area network) communication commands [82].

\section{BMS Cell Settings}

The correct order of setting the battery and cells parameters would be to first adjust the settings under balancing and state of charge (SOC) group boxes in the cell settings tab of the battery insider, Annex 1.

Then, on the safety tab, adjust the cells critical parameters over-voltage cutoff and under-voltage cutoff. Upload the settings again to the device.

Only then go back to the cell settings tab and adjust fully charged voltage and fully discharged voltage parameters accordingly. These settings have a relationship under-voltage cutoff $<$ fully discharged voltage $<$ fully charged voltage $<$ over-voltage cutoff, and the Battery Insider will not allow the user to set these values in any other way which would contradict the parameters relationship. 
BMS Temperature Sensor Configuration

NTC (negative temperature coefficient) thermistors $10 \mathrm{~K}$ at $25^{\circ} \mathrm{C}$ are used in the battery pack, the temperature sensor type parameter should be configured to Dual 10K NTC Sensor, Annex 1.

Once the previous parameters are correctly configured, it is in position to go into the battery insider live data tab (1) where the following parameters are shown, Figure 8:

- Cells voltage graph (2)

- Charging/discharging current status bar (3)

- $\quad$ BMS current operation state (4)

- $\quad$ BMS last recorded event (5)

- $\quad$ BMS estimated SOC value (6)

- Battery pack voltage calculated as the sum of all individual cells voltage connected in series (7)

- $\quad$ Battery pack current (8)

- Minimal battery pack cell voltage (9)

- Maximal battery pack cell voltage (10)

- $\quad$ BMS on board NTC temperature sensor value (11)

- External NTC temperature sensor \#1 value (12)

- External NTC temperature sensor \#2 value (13)

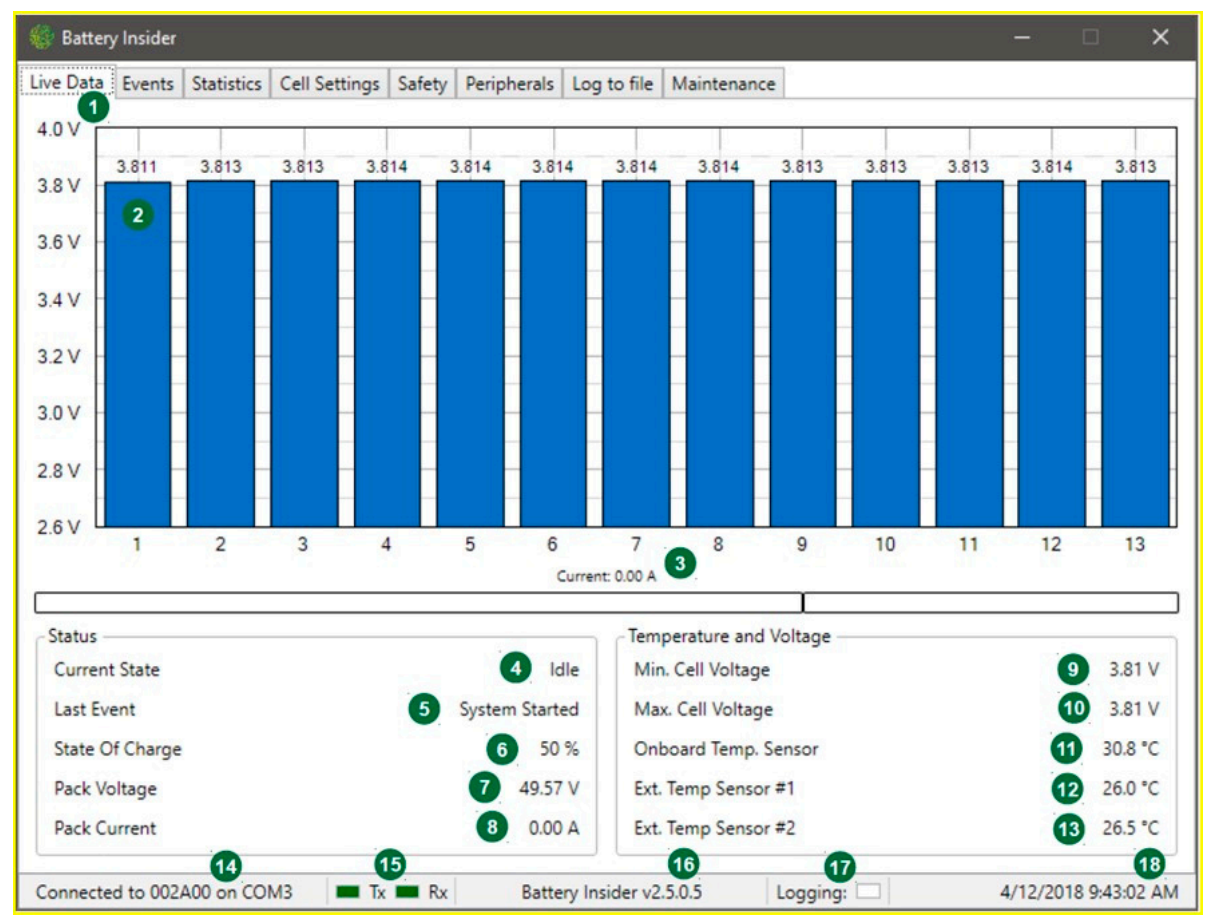

Figure 8. Live data tab parameters.

\subsubsection{Propeller}

As mentioned in the introduction of the present paper, one of the changes in the elements introduced in this new version of the ALO is the replacement of the two-bladed propeller with a carbon fiber three-bladed propeller with similar thrust. The mounted propeller is the model $28 \times 123$-Blatt. Table 8 shows its detailed dimensions and characteristics of the propeller mounted on the RPA. 
Table 8. ALO propeller main characteristics.

\begin{tabular}{cc}
\hline Type & Three-Bladed \\
\hline Diameter & $28^{\prime \prime}$ \\
Pitch & $12^{\prime \prime}$ \\
Weight & $364 \mathrm{~g}$ \\
Max. rpm & 8000 \\
shaft diameter & $10 \mathrm{~mm}$ \\
\hline
\end{tabular}

Made of carbon fiber, its main characteristic is lightness, as well as its specific rigidity, with a low-noise emission level for high rpm. In addition, the central mount has a wood reinforcement. The profile used is Clark Y, widely used in the aeronautical industry for general uses. It has a relative thickness of $11.7 \%$, with a maximum thickness of $30 \%$ of the rope.

\subsubsection{Telemetry Module}

\section{Emitter}

The emitter is installed in the ALO and does not interfere with any other elements of the RPA, making the telemetry module completely autonomous and not dependent on the ALO battery pack. The emitter consists of the following elements (Figure 9): Microcontroller Arduino NANO, Real-time clock (RTC), SD card slot, and a $2.4 \mathrm{GHz}$ Xbee module. To power all these elements, two 3.6 Ah LiPo batteries were installed in the back of the emitter module.

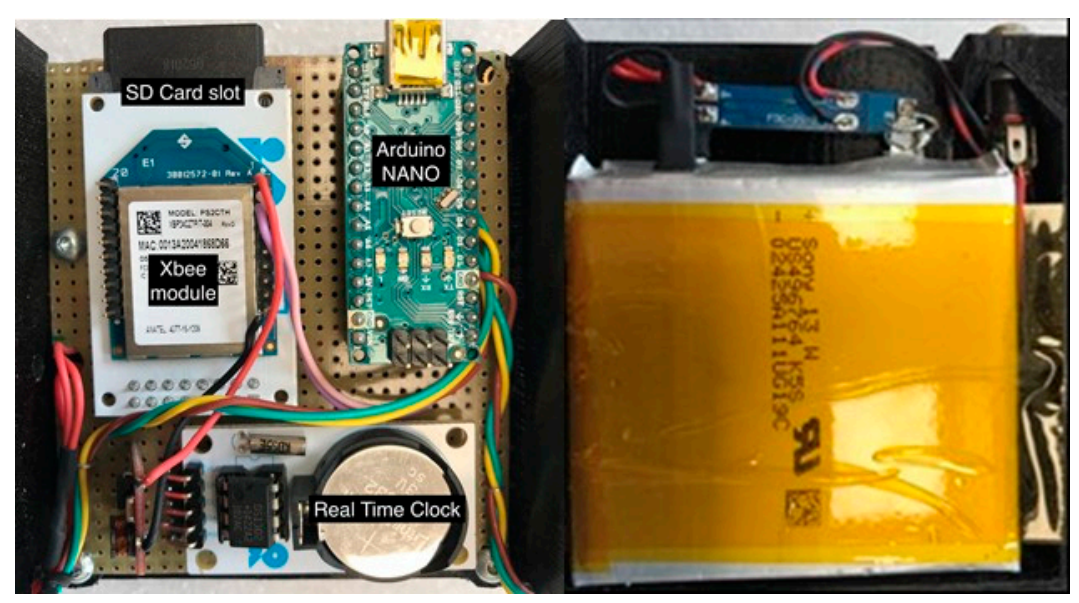

Figure 9. Emitter module front and rear view.

The emitter is able to communicate with the main battery pack BMS and the motor controller. This way it is possible to check all the parameters during tests and during take-off phase.

In the event of loss of communication, the emitter module is equipped with an SD memory card that saves all the data, acting as an onboard black box. Once on the ground, it is possible to collect the SD card and analyze all the flight data.

Receiver

The receiver module (Figure 10) is plugged in a PC USB port and consists of a $2.4 \mathrm{GHz}$ Xbee module and an antenna. 


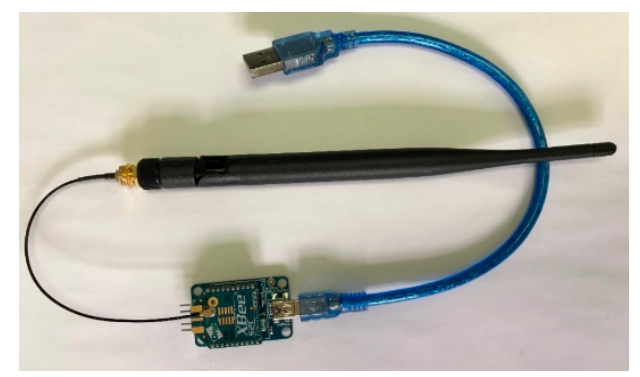

Figure 10. Receiver: Xbee card with antenna and USB cable.

The receiver receives data from the emitter and, through the USB port, communicates with a custom software developed under Labview $(\mathcal{C}$ environment, by National Instruments $($, that allows the operator to check live parameters, Figure 11.

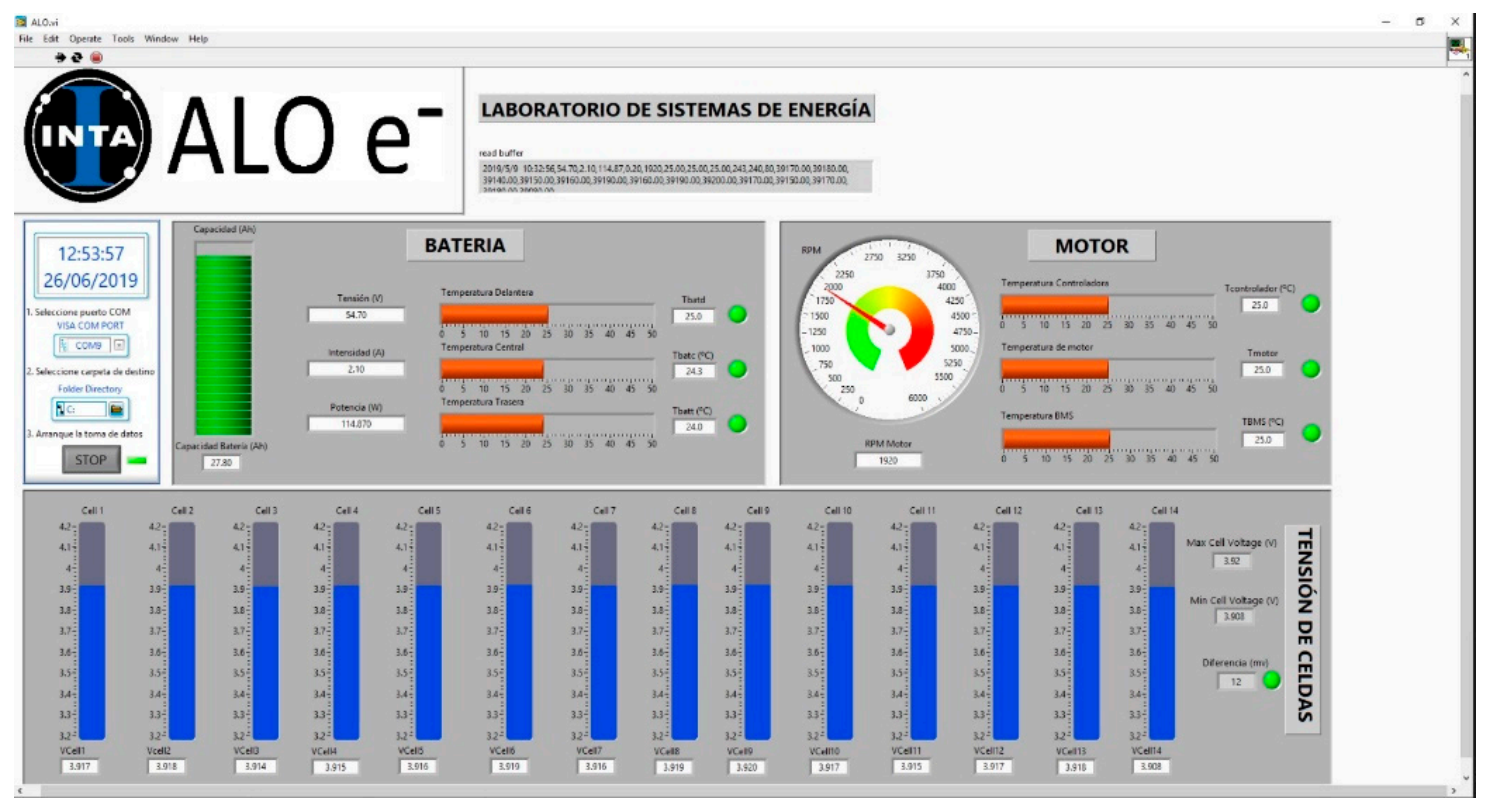

Figure 11. Developed SCADA software for electric ALO platform.

The software uses serial $8 \mathrm{~N} 1$ communication protocol at 9600 bauds. $8 \mathrm{~N} 1$ is a common abbreviation for the configuration of the serial port in asynchronous mode where there are eight (8) data bits, no $(\mathrm{N})$ parity bit, and one (1) stop bit. With this configuration, only $80 \%$ of the data transmit information, since every 10 bits one is used for the start and end of each piece of information: The byte. $8 \mathrm{~N} 1$ is the most common configuration for serial port communications at the INTA Energy Systems Laboratory. The transmission rate is usually in bits per second (bauds), such as 9600 . The software is configured to ask the transmitter once per second for the incoming data (data string), which will be no longer than 300 characters. This transmission frequency, $1 \mathrm{~Hz}$, is more than enough for live plotting and for post-flight data analysis.

The data string contains checksum detection. This checksum is a redundancy function whose main purpose is to detect accidental changes in the sequence of data to protect their integrity and to verify that there are no discrepancies between the controlled values when making an initial and final check after the transmission. The idea is that the data is transmitted along with its checksum value so the software calculate that value and compare it with the checksum value received. If there is a discrepancy, the software is able to reject the data or request a retransmission. Normally, increasing the ability to detect errors in the transmission increases the complexity of the algorithm, and with it, the required process needs, which in the present work is not a problem since the processor is a dedicated 
laptop. However, it provides means for reliably detecting errors in the transmission. This software shows the main parameters related to the new power supply system of the electric ALO such as: remaining battery capacity, instant battery current and voltage, battery pack temperature sensors values, battery pack individual cell voltage and main motor parameters, such as, motor temperature and motor rpm. There are four different charts in the software main window. The small white chart shows communication parameters in the computer and in the path to the saving file. The next chart is for the main information of the battery pack, like temperature, voltage, current, and remaining capacity. The chart on the right side shows motor parameters as rpm and different elements temperatures. In the bottom chart there are information about individual battery cells in order to check the behavior of each cell in each situation. All these charts show the information using graphics, displays, and error lights to easily understand the operation of the system and to make decisions if there is any problem. All these values are also saved in a file for later analysis.

\subsection{Auxiliary Testing Platforms}

In order to test the RPA in safety environments and check the performance of the modified elements, the following auxiliary testing platforms are needed:

\subsubsection{Arbin Battery Test Bench}

In order to carry out the different tests to the battery individual cells and the battery pack the Arbin MT-ML-40V-20-2Chanels [83,84] battery testing system was used (Figure 12). This battery testing system provides:

- Fully independent high-precision test channels with full potentiostatic, galvanostatic control.

- True bipolar linear circuitry providing cross-zero linearity and zero switching time between charge and discharge.

- $\quad$ Each channel provides 3 or 4 current ranges with 16-bit resolution.

- Powerful embedded controllers provide fast data logging (2000 points per second, per system) and control flexibility for the most advanced test requirements.

- Any number of channels can be operated in parallel for increased current-handling capacity.

- Communicate with internal BMS via CANBus or SMBus protocols.

- Systems are air-cooled so no additional facility infrastructure or regular maintenance is needed.

- Software provides easy data analysis and plotting based in Data Watcher and Microsoft Excel.

- A wide array of auxiliary inputs/outputs are available for additional data collection or control such as temperature monitoring, additional reference electrodes, and more. Table 9 summarizes the main characteristics and Figure 12 shows a detail of the battery test bench.

Table 9. Arbin(C) battery test bench characteristics.

\begin{tabular}{ll}
\hline Number of Channels & $\mathbf{4}$ \\
\hline Voltage range & 0 to $60 \mathrm{~V}$ \\
Control and voltage measurement accuracy & $( \pm 0.05 \% \mathrm{FSR}$ (full scale range) $\pm 60 \mathrm{mV}$ \\
Min voltage to max current & $0 \mathrm{~V}$ \\
Input impedance & $\sim 10 \mathrm{G} \Omega$ \\
Max current (charge/discharge) & $100 \mathrm{~A}$ \\
Current and voltage resolution & $16 \mathrm{bits}$ \\
Current ranges $( \pm 0.05 \%$ FSR (full scale range)) & \\
(a) High & $100 \mathrm{~A} \pm 100 \mathrm{~mA}$ \\
(b) Medium & $10 \mathrm{~A} \pm 10 \mathrm{~mA}$ \\
(c) Low & $1 \mathrm{~A} \pm 1 \mathrm{~mA}$ \\
Current rise time & $3 \mathrm{~ms}$ \\
\hline
\end{tabular}




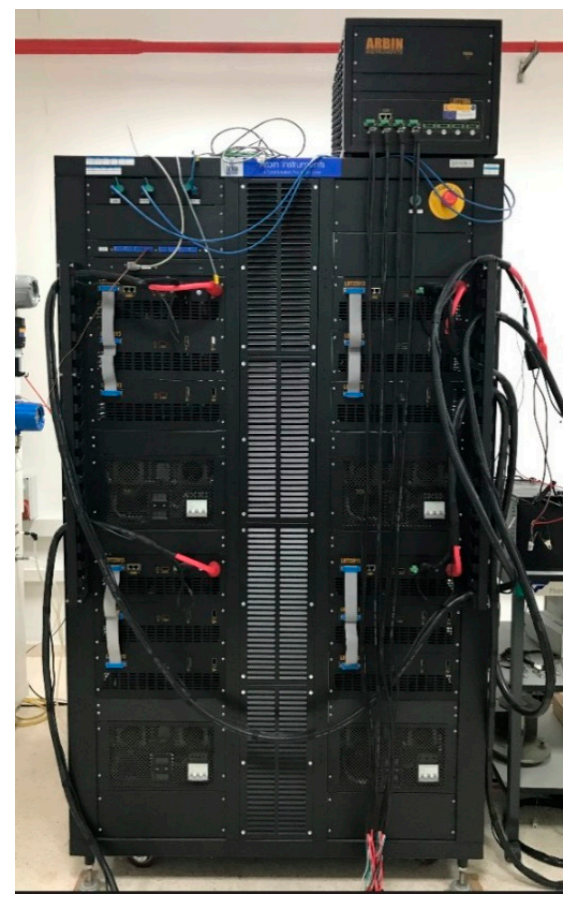

Figure 12. Arbin (C) battery test bench.

\subsubsection{Thrust Test Bench}

Due to the nature of all the modifications performed in the original ALO, a thrust test with the original ICE configuration and with the final configuration of the electric ALO was driven, in order to ensure the global behavior of the complete system and to be able to compare the on ground thrust for both the original and the final electric configurations. For that reason, a test bench was specifically designed to measure the real thrust of the system considering the new electric power plant, the motor controller, the electric motor, and the new 3-blade propeller (Figure 13).

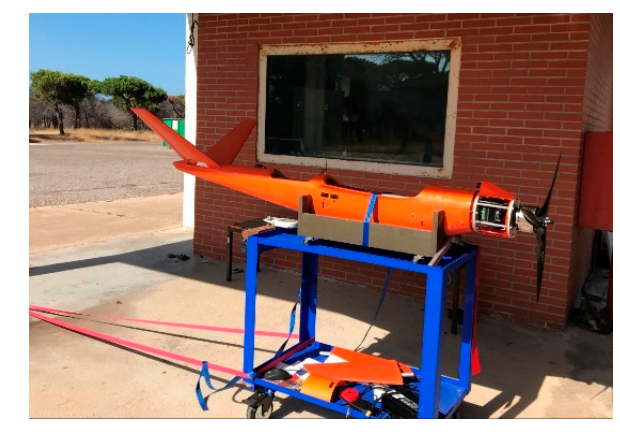

a)

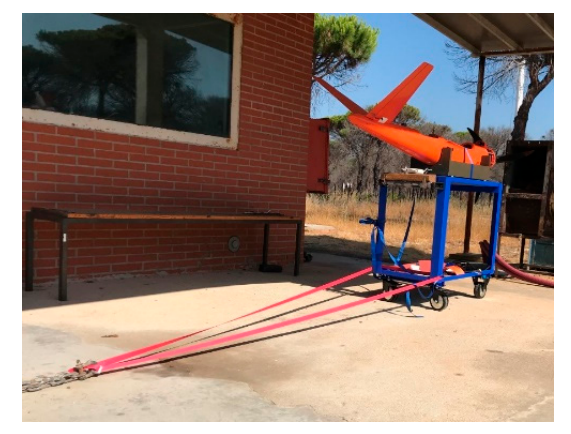

b)

Figure 13. Modified electric ALO in thrust test bench. (a) lateral view, (b) stern view.

This test bench is based on a trolley securely attached to the ground by means of slings and carabiners. On top of this trolley the ALO is installed on a wheeled cradle attached to the main trolley with a dynamometer. These wheels allow the cradle to freely move forward/backwards and pull the dynamometer axle.

For safety reasons, the test bench was installed in an appropriate hangar for motor/turbine test equipped with a security glass window. 


\subsubsection{Launcher}

To launch these types of RPAS, they need an initial boost. The most widespread way to give this momentum is by using a launching ramp. The ramp used in these tests was a Kinetic Energy Catapult Launcher manufactured by QuinetiQ@ Target Systems. This launching system is elastic based and the amount of energy transmitted to the plane depends on how many dual elastic bands are used (Figure 14).

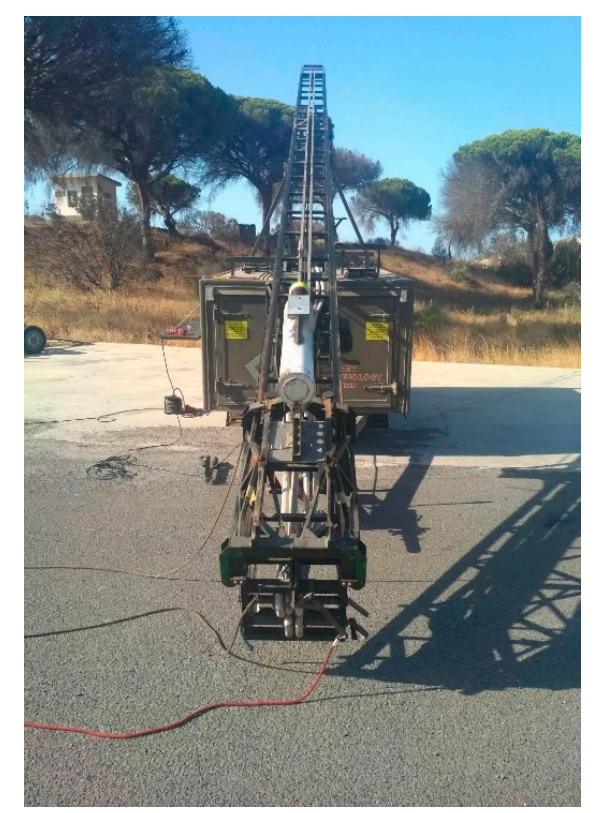

Figure 14. Detail of the QinetiQ@ Energy Catapult launcher with a dummy on the ramp.

The catapult launcher was designed to launch targets at an angle of $20^{\circ}$ and speeds in excess of

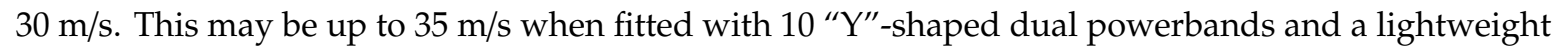
ALO RPA. ALO launch speed is indicated by a launch speed indicator supplied with the launcher.

\section{Experimental Results}

The objective of this section is to check the proper operation of the adapted electric ALO. In previous works (see Annexes 2,3, and 4), the different flight modes for this UAV were determined, as well as the energy needed for them. Table 10 shows a summary of the energy needs of each of the phases of the main flight plan that will have a cruising speed and altitude of $32 \mathrm{~m} / \mathrm{s}$ and $720 \mathrm{~m}$, respectively.

Table 10. Energy requirements for each phase of the main flight plan.

\begin{tabular}{ccccccc}
\hline & $\mathbf{V}_{\mathbf{0}}(\mathbf{m} / \mathbf{s})$ & $\mathbf{V}_{\mathbf{f}}(\mathbf{m} / \mathbf{s})$ & $\gamma\left({ }^{\circ}\right)$ & $\mathbf{t}(\mathbf{m i n})$ & Max Power $(\mathbf{k W})$ & $\mathbf{E}(\boldsymbol{J})$ \\
\hline Phase 1 of ascent & 15 & 32 & 10 & 0,6 & 3.910 & $1047 \times 10^{5}$ \\
Phase 2 of ascent & 32 & 32 & 10 & 1.78 & 2.706 & $4843 \times 10^{5}$ \\
Cruise & 32 & 32 & 0 & 90 & 0.544 & $2927 \times 10^{6}$ \\
Descent phase & 32 & 28.5 & 2.54 & 6.75 & 0 & 0 \\
TOTAL & - & - & - & 98.89 & - & $3516 \times 10^{6}$ \\
\hline
\end{tabular}

Phase 1 of ascent: The first phase is immediate to the launching of the aircraft from the ramp and will consist of a rectilinear ascent with constant acceleration, until reaching $32 \mathrm{~m} / \mathrm{s}$, with an angle of ascent of $10^{\circ}$. The height reached is around $120 \mathrm{~m}$. 
Phase 2 of ascent: Once reached the previous level of $120 \mathrm{~m}$ and the speed of $32 \mathrm{~m} / \mathrm{s}$, the ascent continues. Due to the need to stay close to the coast, it is necessary to carry out the ascent to the height of $720 \mathrm{~m}$ cruise flight in a small space. Therefore, an ascent will be made following a helical path.

Cruise: The phase of flight corresponding to cruise will take place at an altitude of $720 \mathrm{~m}$, and at a speed of $32 \mathrm{~m} / \mathrm{s}$. With the aim of causing turns in the aircraft, both right and left, the layout of an eight-shaped circuit was chosen.

Descent phase: This last phase of the flight will consist of a gliding flight from an altitude of $720 \mathrm{~m}$ and a speed of $32 \mathrm{~m} / \mathrm{s}$, to a height of $200 \mathrm{~m}$ and an approximate speed of $25 \mathrm{~m} / \mathrm{s}$, at which time the parachute will be deployed prior to recovery.

Regarding the different phases of the flight plan described above, the experimental tests must be focused on (1) testing the capacity of the electric power supply system (battery test), (2) checking the dynamometer value and power consumption with different throttle demands (thrust test), and (3) determining the number of dual elastic bands needed to appropriately launch the RPA (launching dummy tests). Next, the experimental results obtained from each category test are presented.

\subsection{Battery Tests}

Extensive tests were performed to the individual battery cells and the battery pack in order to ensure its performance during a typical flight.

\subsubsection{Battery Individual Cell Tests}

As per the battery product specification datasheet [76], standard charge and discharge procedure were carried out to the battery individual cells to check their condition one month after delivery and to confirm the capacity stated by the manufacturer.

The battery individual cells were charged to $4.2 \mathrm{~V}$ with $8 \mathrm{~A}(\mathrm{C} 0.5)$, from constant current to constant voltage, Figures 15 and 16, interval $0<$ time $<1700 \mathrm{~s}$. When the SOC achieves $95 \%$, the charge is stopped. Then they were discharged at $8 \mathrm{~A}(\mathrm{C} 0.5)$ until the voltage decreased up to $3.0 \mathrm{~V}$. After $10 \mathrm{~min}$ rest, the individual cells were charged again following the standard charging procedure.

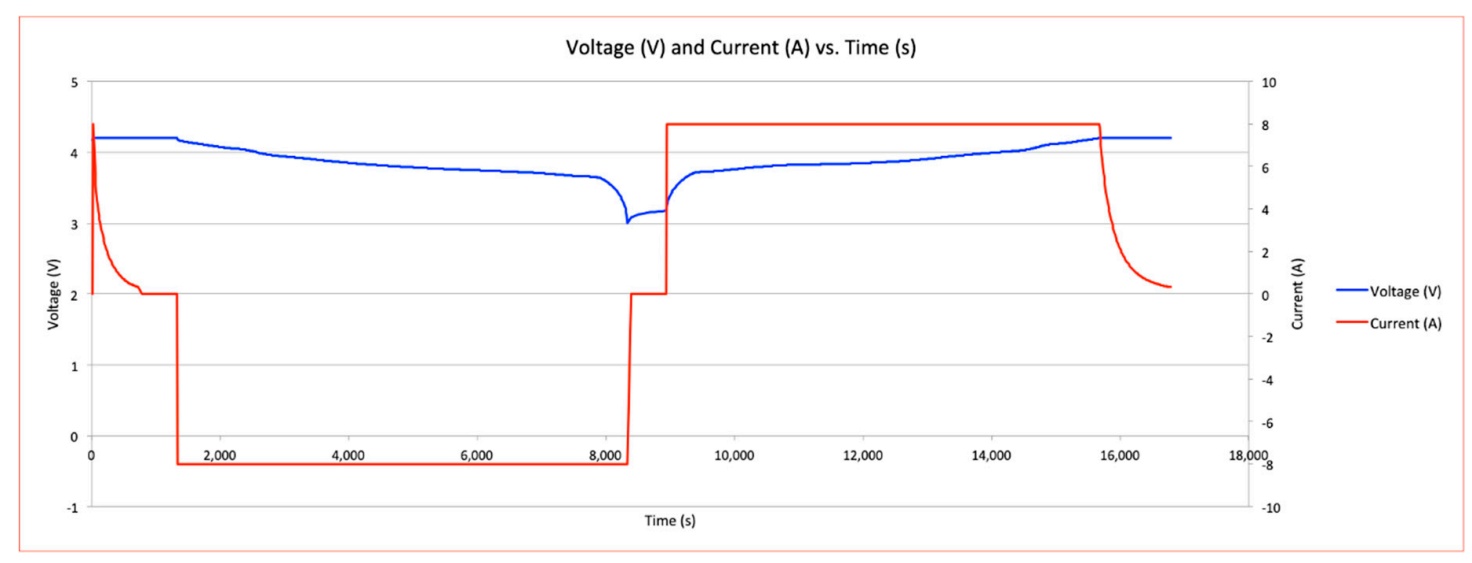

Figure 15. Battery individual cell testing: Voltage and current vs. time. 


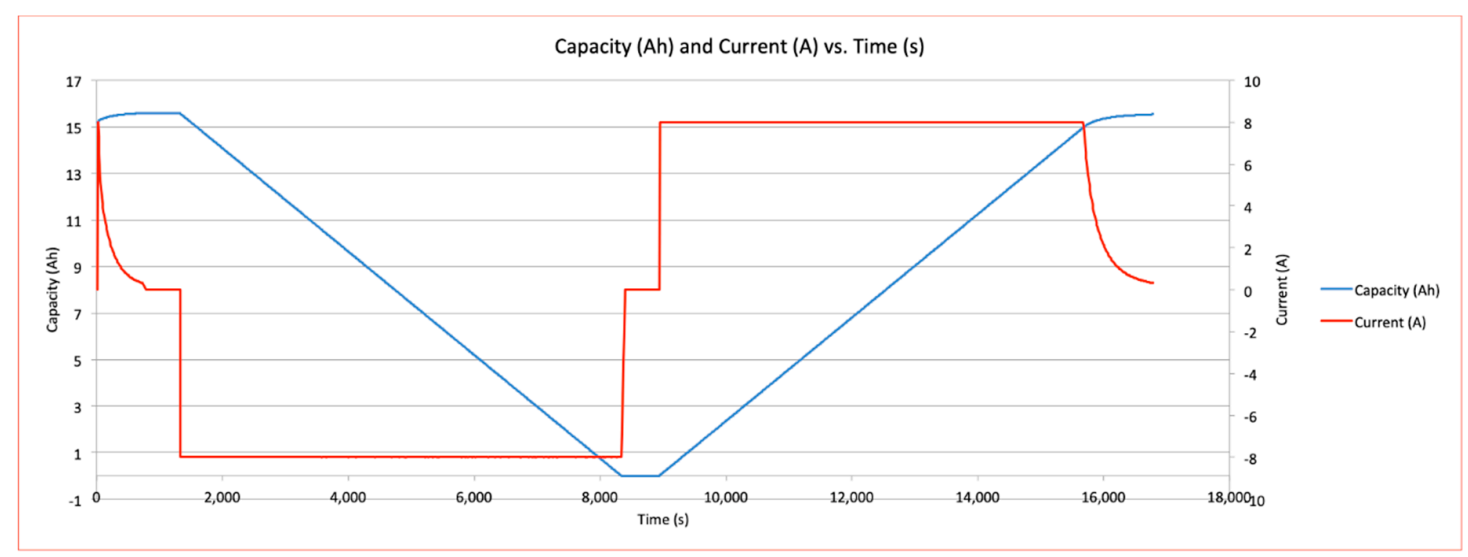

Figure 16. Battery individual cell testing: Capacity and current vs. time.

Flight Load Profile

In order to ensure the behavior of the battery individual cells during the flight, they were tested under a typical flight load profile.

This profile, as can be seen in the Figures 17 and 18, starts with 4 min demanding $4 \mathrm{KW}$, which corresponds to the launching needs and, after that, the power demand decreases to $1 \mathrm{KW}$, which is enough to ensure a stable cruise speed at $30 \mathrm{~m} / \mathrm{s}$. The experiment shown in the Figures 17 and 18 also includes a $10 \mathrm{~min}$ rest period after the discharge under the flight load profile and the subsequent recharging of the battery.

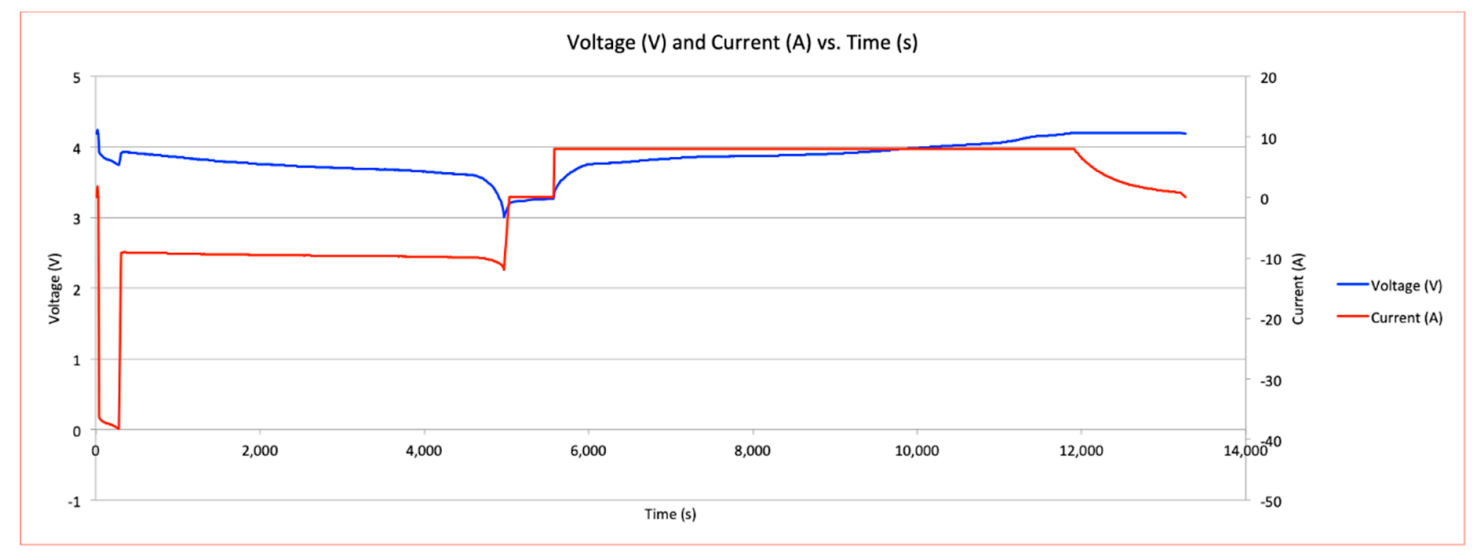

Figure 17. Battery individual cell testing under flight load profile: Voltage and current vs. time.

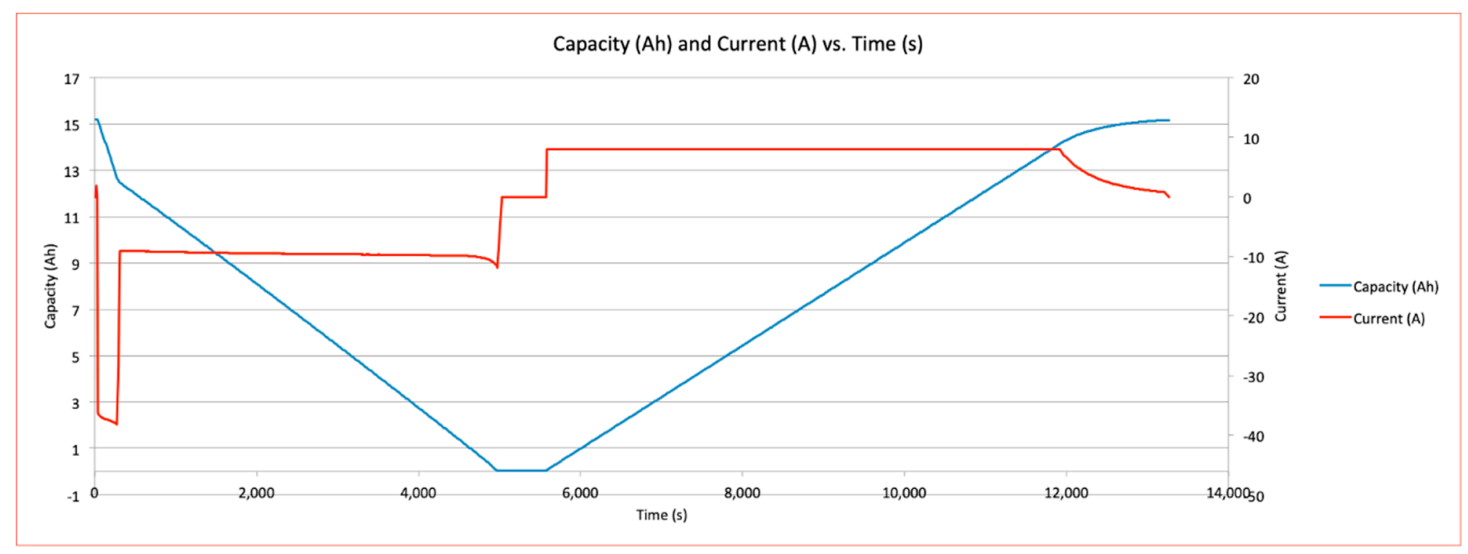

Figure 18. Battery individual cell testing under flight load profile: Capacity and current vs. time. 
These power values are referred to the complete battery pack, so, in order to test the battery pack, individual cells were proportionally scaled taking into account the battery pack setup (14S2P).

The power needed in the original ALO, both during launching and cruise, is stablished regarding the total power of the motor $(6.8 \mathrm{HP})$ and the percentage of throttle commanded by the pilot.

During the launching, this percentage of throttle will vary with the wind conditions but it can be considered as standard in most of the duration of the launching. The percentage of throttle in the majority of the launchings is stablished at 70\% [85-87]:

$$
\begin{gathered}
6.8 \mathrm{HP}=5070.76 \mathrm{~W} \\
5070.76 \mathrm{~W} \times 70 \%=3549.53 \mathrm{~W}
\end{gathered}
$$

The percentage of throttle needed during cruise in the original ALO will be affected by weather conditions and flight altitude, but it can be considered as standard in the major part of the typical flights. The value of throttle in the majority of cruise situations was established at $15 \%$ :

$$
\begin{gathered}
6.8 \mathrm{HP}=5070.76 \mathrm{~W} \\
5070.76 \mathrm{~W} \times 15 \%=760.61 \mathrm{~W}
\end{gathered}
$$

Thus, it can be confirmed that the values of 4 and $1 \mathrm{~kW}$, which were used during testing a typical flight load profile, are more demanding than during a normal flight.

\subsubsection{Battery Pack Tests}

The battery pack was tested under the typical flight load profile to ensure its endurance when in flight. It should be noted that this flight profile is quite demanding. The final result of flight autonomy will be greater than that obtained in this test bench because the cut-off voltage will be lowered to $42 \mathrm{~V}$ when real operations will take part.

Figures 19 and 20 correspond to the test performed to the battery pack under flight load profile. The first step of this profile demands $4 \mathrm{KW}$ during $4 \mathrm{~min}$. Figure 19 shows the voltage decrease due to the high current demand. In the second step, with a demanding power of just $1 \mathrm{KW}$, the voltage increases around $1.5 \mathrm{~V}$ due to the change on demanding current. Figure 20 shows the remaining capacity of the battery pack and how the capacity decreases faster in the first step of the simulation when the power demand is higher.

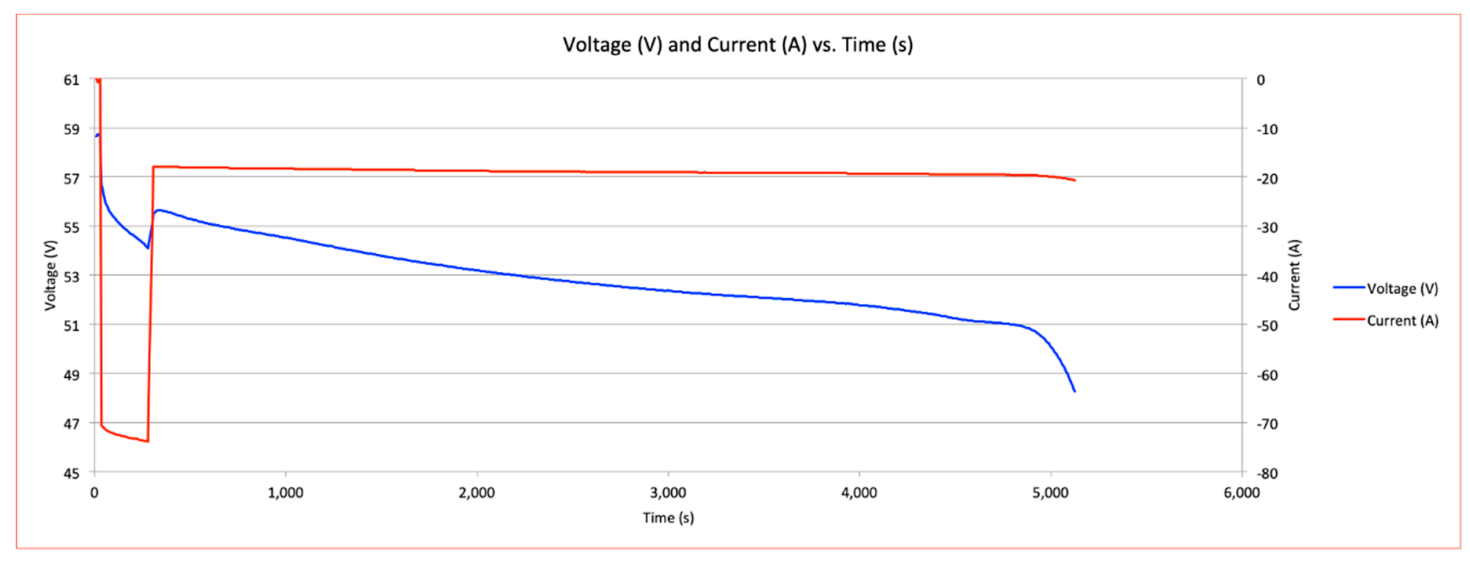

Figure 19. Battery pack test. Battery pack behavior under flight load profile. 


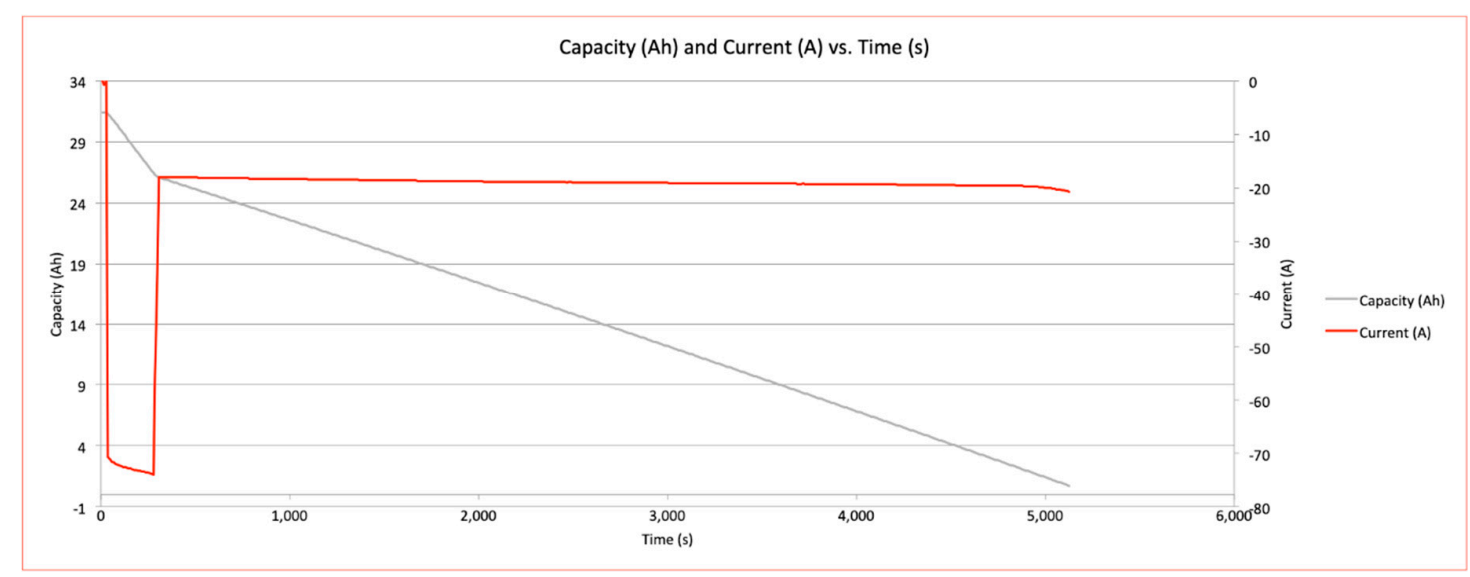

Figure 20. Battery pack test. Battery pack behavior under flight load profile.

As shown in Figure 21, the test starts at $\mathrm{t}=0 \mathrm{~s}$ with $4.20 \mathrm{~V}$ per cell, which corresponds to a battery pack total voltage of $58.80 \mathrm{~V}(4.20 \mathrm{~V} \times 14=58.80 \mathrm{~V})$.

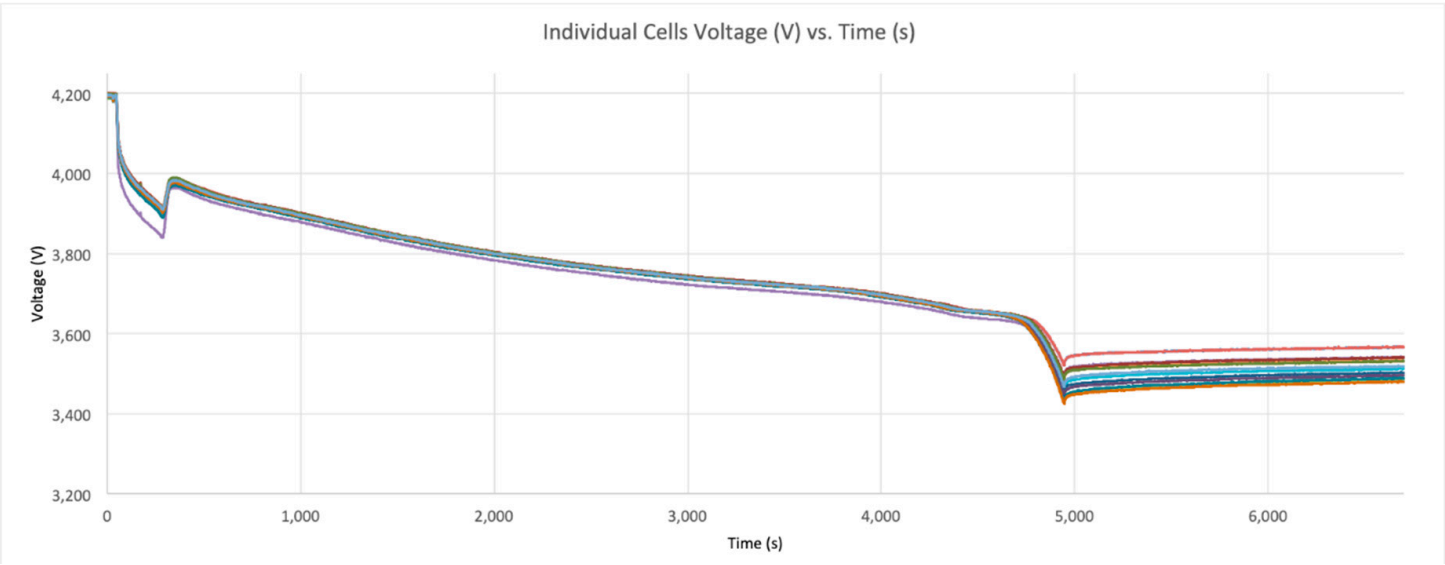

Figure 21. Battery pack test. Individual cells voltage behavior under flight load profile.

The test finishes at $\mathrm{t}=4900 \mathrm{~s}$ with $3.42 \mathrm{~V}$ per cell, which corresponds to a battery pack total voltage of $47.88 \mathrm{~V}(3.42 \mathrm{~V} \times 14=47.88 \mathrm{~V})$.

This test results in an estimated autonomy of around $90 \mathrm{~min}(4900 \mathrm{~s} / 60 \mathrm{~s}=81.6 \mathrm{~min})$.

The battery cells cut-off voltage was stablished in $3.42 \mathrm{~V}$ to avoid unnecessary degradation of cells during the different endurance tests.

This cut-off voltage will be lowered to $3.00 \mathrm{~V}$ [76] when real operations will take part.

Taking into account this lowered cut-off voltage level, it can be assumed that the total estimated autonomy will overcome the $90 \mathrm{~min}$ goal, achieving the total time of $5500 \mathrm{~s}$ ( $5500 \mathrm{~s} / 60 \mathrm{~s}=91.66 \mathrm{~min}$ ).

\subsection{Thrust Tests}

The main objective of the thrust test consists of checking the dynamometer value and power consumption with different throttle demands that will be used in a typical flight mission, while the ALO is installed in the thrust test bench.

When available power, $\mathrm{P}_{\mathrm{A}}$, and power required, $\mathrm{P}_{\mathrm{R} \text { cruisser, }}$, are equal to each altitude, $\mathrm{h}$, the maximum and minimum speeds of the system were obtained under these conditions. Figure 22 (from Annex 3) shows available power and required power for each flight altitude. 


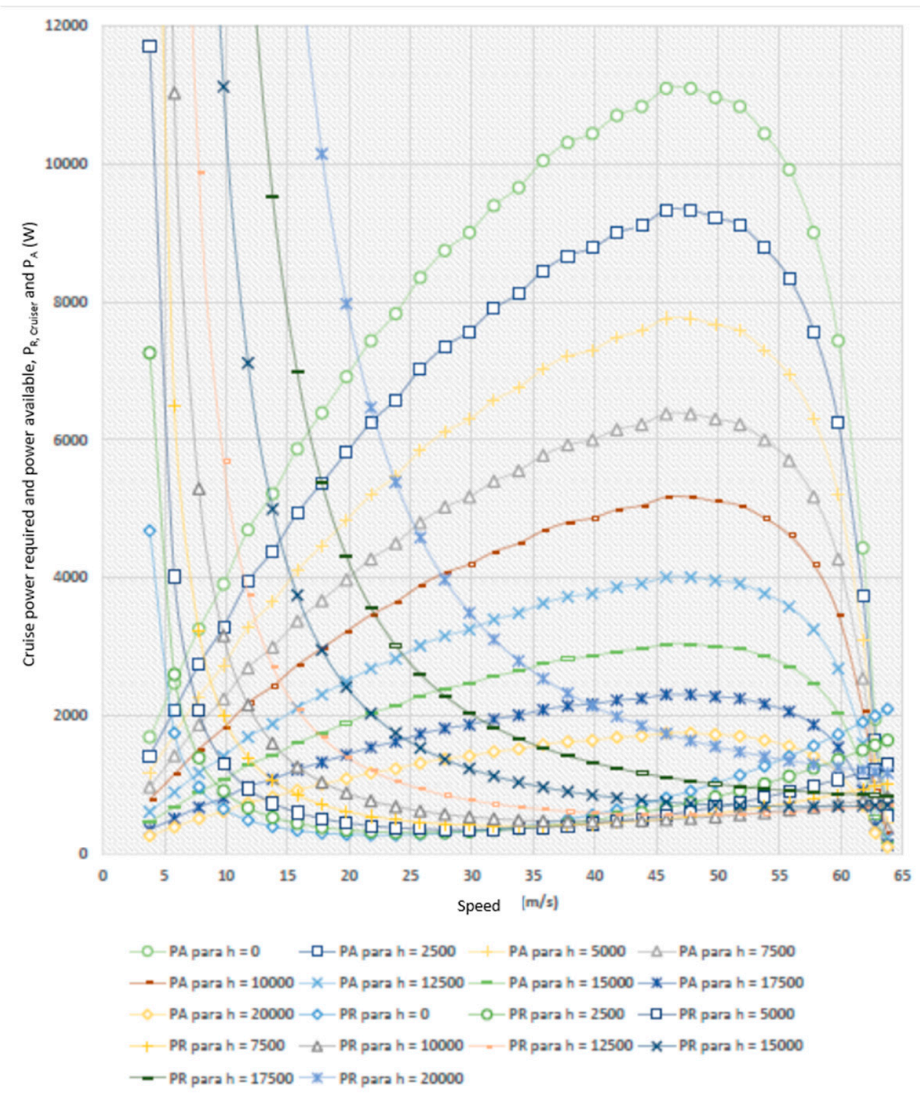

Figure 22. Available power and required power for each flight altitude. Where $\mathrm{P}_{\mathrm{A}}$ is power available $(\mathrm{W})$ and $\mathrm{h}$ is altitude $(\mathrm{m})$.

Experimental results of the electric ALO thrust test are presented in Figure 23. Thrust and power consumption increase with motor input. The launching could be performed at $60 \%$ of engine input, with a power consumption of around $4.5 \mathrm{KW}$ and a thrust of $12 \mathrm{~kg}$. In order to maintain cruise speed when the RPA reaches its objective altitude, a very low thrust is needed and less than $35 \%$ of motor input is enough.

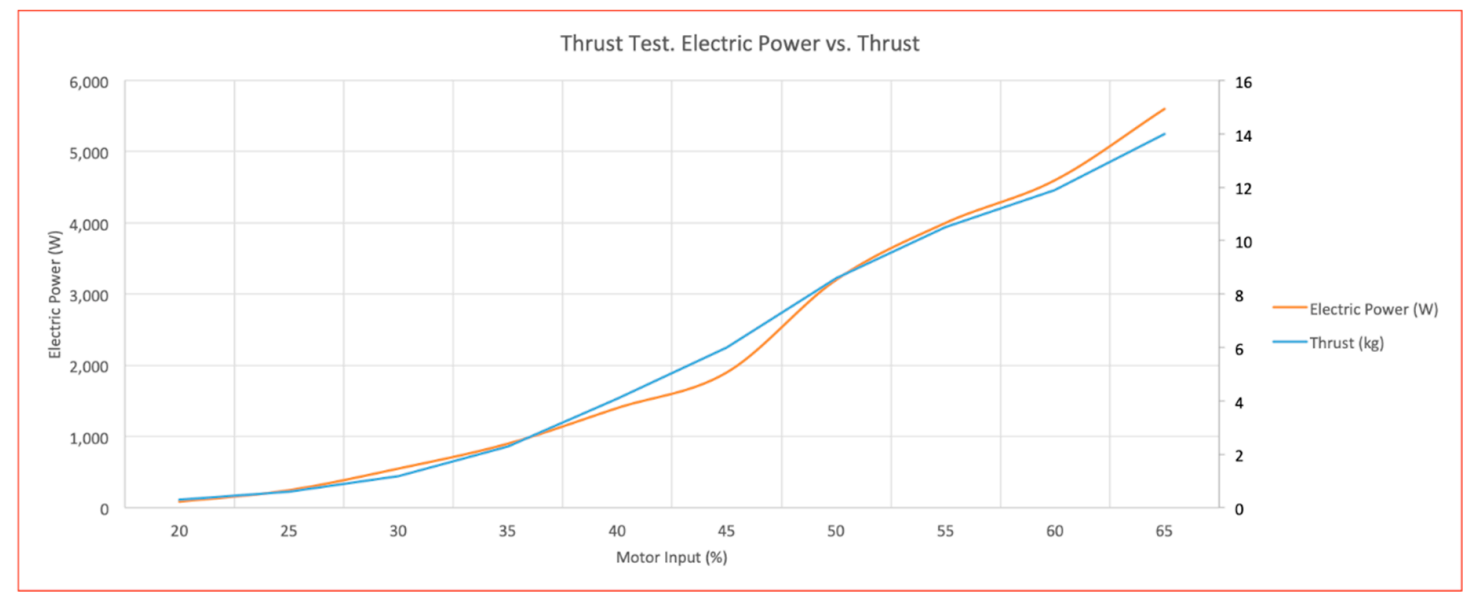

Figure 23. Electric ALO thrust test. Electric power vs. thrust.

Figure 24 shows a thrust comparison between the Electric ALO and ICE configuration. Thrust results confirm that both configurations reach around $12 \mathrm{~kg}$ thrust at $60 \%$ motor input, which would be enough for the launching needs. 


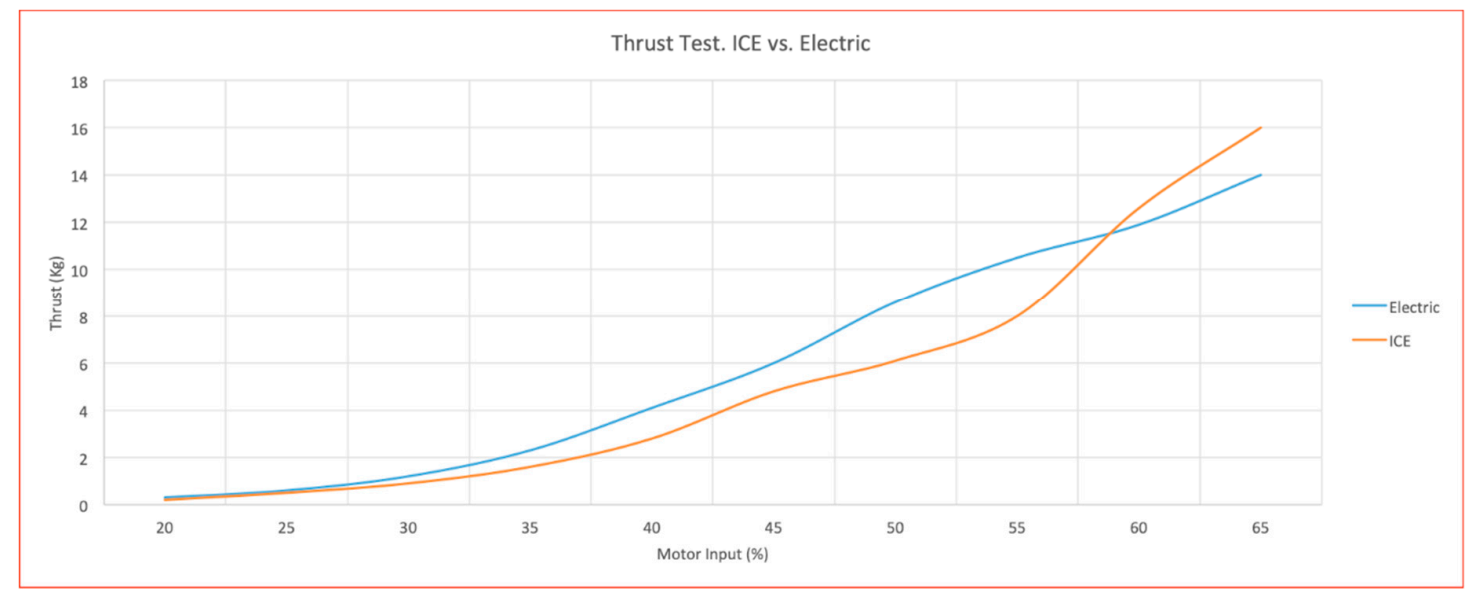

Figure 24. ALO thrust tests: ICE vs. electric configurations.

Since the modifications performed in the original ALO do not affect the weights nor the surfaces, the flight envelope for both configurations are the same. With this static thrust test, it can be assumed that the performance of the modified ALO will be the same when in flight.

\subsection{Launching Dummy Tests}

In order to test the QuinetiQ@ Energy Catapult Launcher with the increased weight of the new electric ALO, a launch test was performed. To make the tests, a dummy was built with the same weight of the new electric ALO, Figure 14.

The experiment performed consists of determining the number of dual elastic bands needed to appropriately launch the RPA. The electric ALO needs to reach a speed of at least $32 \mathrm{~m} / \mathrm{s}$ to take-off (phase 1 of ascent). In order to check different situations, five launchings were performed with different numbers of dual elastic bands and measuring the speed at the end of the launcher in each case. As shown in Figure 25, minimum take-off speed can be ensured using at least 10 elastic bands.

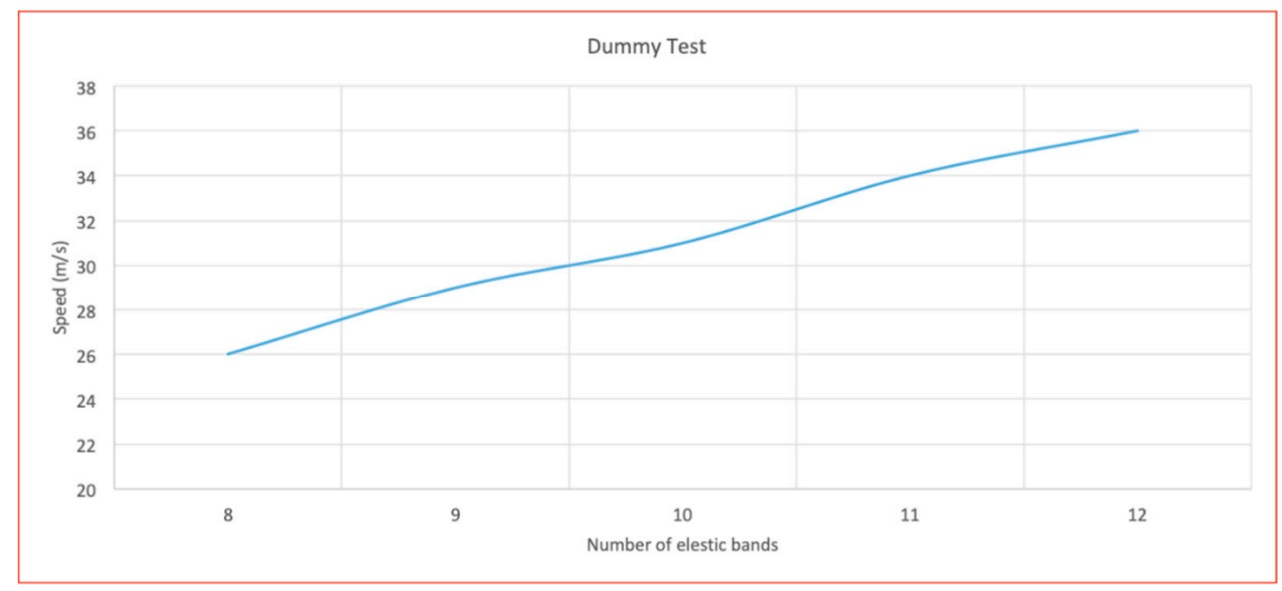

Figure 25. Dummy launching speed test.

In addition, it was found that it is not necessary to count on the old launcher. This QuinetiQ@ Energy Catapult Launcher perfectly fulfills that function.

\section{Discussion}

The tests carried out in the test bench, with the energy storage system (batteries) in the flight regime, indicate that the expected autonomy of this electric unmanned airplane will exceed 90 min of 
flight (Figures 19-21). This represents 50\% more flight autonomy than in its original configuration with the internal combustion engine fueled with gasoline. It should be noted that the flight autonomy tests, to which the electric RPAS was subjected, were based on a very demanding flight profile, so that the final autonomy achieved will surely be greater than the one described. As can be seen from Table 10, the batteries do not consume all the stored energy, calculated in $6156 \times 10^{6} \mathrm{~J}(3)$, in fact it is far from this situation, presenting a surplus of energy of $\Delta \mathrm{E}=2,64 \times 10^{6} \mathrm{~J}$ so it could still be increased even more flight autonomy in cruise mode.

$$
E_{e, \text { batteries }}=200 \frac{W h}{k g} ; m_{\text {batteries }}=8.55 \mathrm{~kg} ; E_{\mathrm{t}, \text { batteries }}=6156 \times 10^{6} \mathrm{~J}
$$

Table 11 reflects the main differences between the two versions of the RPA, the internal combustion engine and the electric, in terms of weight, maximum payload, flight autonomy, emissions and maintenance needs. Figure 26 offers an idea of the comparison of sizes between the new components and the old ones.

Table 11. ICE ALO vs. electric ALO main features.

\begin{tabular}{lcc}
\hline & ICE ALO & Electric ALO \\
\hline Fuselage & $3.50 \mathrm{~kg}$ & $3.50 \mathrm{~kg}$ \\
Motor & $3.50 \mathrm{~kg}$ & $1.90 \mathrm{~kg}$ \\
Propeller & $0.35 \mathrm{~kg}$ & $0.40 \mathrm{~kg}$ \\
FCS (flight control system) & $0.85 \mathrm{~kg}$ & $0.31 \mathrm{~kg}$ \\
Telemetry Module & $0.70 \mathrm{~kg}$ & $0.20 \mathrm{~kg}$ \\
Harnesses & $0.15 \mathrm{~kg}$ & $0.35 \mathrm{~kg}$ \\
Fuel Tanks + Fuel & $6.35 \mathrm{~kg}$ & - \\
Fuel Supply System & $0.27 \mathrm{~kg}$ & - \\
ESC + Mounting & - & $2.39 \mathrm{~kg}$ \\
Main Battery & - & $8.47 \mathrm{~kg}$ \\
BMS + Battery Case & - & $0.95 \mathrm{~kg}$ \\
FCS Auxiliary Battery & $1.76 \mathrm{~kg}$ & $1.37 \mathrm{~kg}$ \\
Weight Without Payload & $17.43 \mathrm{~kg}$ & $19.84 \mathrm{~kg}$ \\
Max. Payload & $7.57 \mathrm{~kg}$ & $5.16 \mathrm{~kg}$ \\
Endurance & $60 \mathrm{~min}$ & $90 \mathrm{~min}$ \\
Emissions & $\mathrm{CO}_{2}+$ CO + NOX & Zero \\
Maintenance Schedule & Every flight & Every 20 flight hours \\
\hline
\end{tabular}

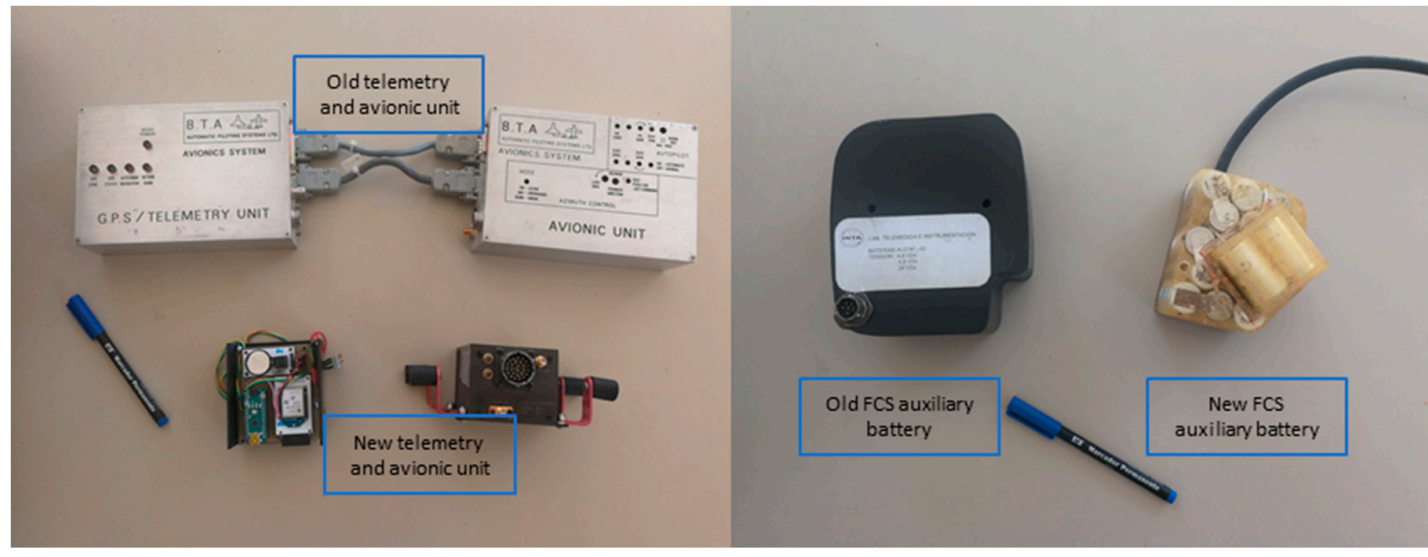

(a)

(b)

Figure 26. Comparison between: (a) old systems used as telemetry and fly control systems and new ones and (b) new and old batteries necessary to feed the FCS. 
Concerning the electricity to recharge the RPAS, INTA has been producing electricity in a renewable way since the 1990s. This comes from several photovoltaic fields of different technologies as well as from a wind turbine. All these renewable energy sources are integrated in a microgrid that can also store excess energy in different types of batteries and in the form of hydrogen [88]. This is the reason why the electric RPAS is considered a zero-emission device; in this case, generation of electric energy does not involve fuel-consuming techniques.

The behavior of the electric engine during the performed thrust tests has been as expected (Figures 22 and 23).

On the other hand, the performed launching dummy tests indicate that the new ALO unmanned aerial vehicle can be launched with the same systems as other RPAS without the need to modify the launcher ramps, which represents an advantage in logistics within the testing center (Figure 14).

Figure 27 represents the electric RPA ready to fly.

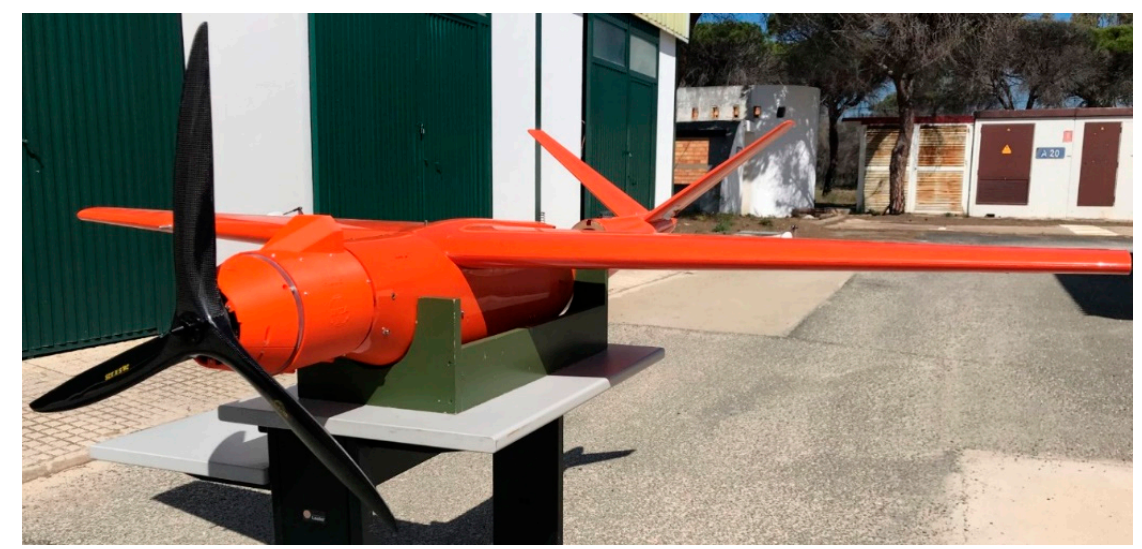

Figure 27. Electric ALO unmanned aerial vehicle ready to fly.

\section{Conclusions and Future Works}

This paper presents a real and practical case of a transformation of a fixed-wing unmanned aerial system, used as an aerial target and powered by an internal combustion engine, in an electric RPA for use in the cultivation of olive trees and other species that occupy large areas of land. Similarly, and taking advantage of one of the main characteristics of electric airplanes, such as its low-noise level, this electric RPA could be used in protected environments, such as natural parks, for the surveillance and supervision of different animal species.

The main reason for carrying out this transformation is to increase the flight autonomy of the RPA in order to be able to take measurements of the different parameters that affect a large-scale crop. This purpose was achieved by increasing the range by almost 50\% compared with the ICE model, and much more if it is compared with the electric multicopters actually used in the project TecnOlivo. The payload was reduced but the increase in flight autonomy compensates this decrease. If compared with other commercial electric fixed-wing UAVs (Table 12), it can be realized that new features of the electric ALO can be compared with them, even improving them in most of the cases.

On the other hand, the present work is an intermediate step to complete an RPA that is moved with hydrogen. Future works on this aerial platform will consist of replacing some of the batteries on board with a hydrogen-based system and fuel cells. In this way it is intended to further increase the autonomy of the UAV [89,90]. The INTA laboratory has vast experience (since 1990) in hydrogen technology and fuel cells and this is not the first RPAS built at INTA based on hydrogen and fuel cells [91]. Thu, in the following months, a new RPA with hydrogen on board will be flying across the sky. 
Table 12. Comparison of some commercial fixed-wing UAVs with the electric ALO.

\begin{tabular}{cccc}
\hline Model & Max. Payload (kg) & MTOW $\mathbf{( k g )}$ & Autonomy (min) \\
\hline Fulmar X & 8.0 & 19 & 400 \\
FV1-ATyges & 2.0 & 4.2 & 180 \\
Electric ALO & 5.1 & 25 & 90 \\
WingtraOne & 0.8 & 4.5 & 55 \\
Firebird FPV & 0.1 & 1.2 & 30 \\
DV Wing & 0.1 & 0.94 & 85 \\
Lancaster 5 & 1.0 & 2.4 & 45 \\
Fulmar X & 8.0 & 19 & 400 \\
\hline
\end{tabular}

Author Contributions: Conceptualization, F.I.L., Á.F.B. and J.A.B.; Methodology, F.I.L., F.S. and J.M.A.; Software, Á.F.B. and J.A.B; Validation, F.I.L., Á.F.B. and J.A.B.; Formal Analysis, F.I.L., Á.F.B. and J.A.B.; Investigation, F.I.L., Á.F.B. and J.A.B.; Resources, F.I.L., Á.F.B., J.A.B., F.S. and J.M.A.; Data Curation, Á.F.B. and J.A.B.; Writing Original Draft Preparation, F.I.L.; Writing - Review \& Editing, all; Visualization, F.I.L.; Supervision, F.S. and J.M.A.; Project Administration, F.I.L.; Funding Acquisition, F.I.L. All authors have read and agreed to the published version of the manuscript.

Funding: Part of this work was supported by "Tecnologías para el manejo y supervisión del cultivo del olivo (Tecnolivo)", a project of the program Interreg V-A España-Portugal (POCTEP 2014-2020) and was co-funded by FEDER (0115_TECNOLIVO_6_E).

Acknowledgments: The authors would like to thank Manuel Gil for his helpful advice in various technical issues regarding the testing platform.

Conflicts of Interest: The authors declare no conflicts of interest.

\section{List of Acronyms}

$\begin{array}{ll}\text { BMS } & \text { Battery management system } \\ \text { CAN } & \text { Controller area network } \\ \text { ESC } & \text { Electronic speed controller } \\ \text { DSM } & \text { Digital surface models } \\ \text { FCS } & \text { Flight control system } \\ \text { FLIR } & \text { Forward-looking infrared } \\ \text { GCS } & \text { Ground control station } \\ \text { HP } & \text { Horse power } \\ \text { ICE } & \text { Internal combustion engine } \\ \text { IGBT } & \text { Insulated gate bipolar transistor } \\ \text { LiPo } & \text { lithium-ion polymer } \\ \text { MOSFET } & \text { Metal-oxide-semiconductor field-effect transistor } \\ \text { NIR } & \text { Near infrared } \\ \text { NGFCS } & \text { Navigation guidance and flight control systems } \\ \text { NTC } & \text { Negative temperature coefficient } \\ \text { PWM } & \text { pulse-width modulation } \\ \text { RGB } & \text { Read green blue } \\ \text { RPA } & \text { Remotely piloted aircraft } \\ \text { RPAS } & \text { Remotely piloted aircraft system } \\ \text { Rpm } & \text { Revolutions per minute } \\ \text { SOC } & \text { State of charge } \\ \text { UART } & \text { Universal asynchronous receiver-transmitter } \\ \text { UAS } & \text { Unmanned aerial system } \\ \text { UAV } & \text { Unmanned aerial vehicles }\end{array}$

\section{References}

1. Granshaw, S.I. RPV, UAV, UAS, RPAS ... or just drone? Photogramm. Rec. 2018, 33, 160-170. [CrossRef] 
2. Chiesa, S.; Fioriti, M.; Fusaro, R. MALE UAV and its systems as basis of future definitions. Aircr. Eng. Aerosp. Technol. 2016, 88, 771-782. [CrossRef]

3. Valavanis, K.P.; Vachtsevanos, G.J. Handbook of Unmanned Aerial Vehicles; Springer Reference: New York, NY, USA, 2015; ISBN 9789048197071.

4. Puri, V.; Nayyar, A.; Raja, L. Agriculture drones: A modern breakthrough in precision agriculture. J. Stat. Manag. Syst. 2017, 20, 507-518. [CrossRef]

5. Shi, Y.; Thomasson, J.A.; Murray, S.C.; Pugh, N.A.; Rooney, W.L.; Shafian, S.; Rajan, N.; Rouze, G.; Morgan, C.L.S.; Neely, H.L.; et al. Unmanned Aerial Vehicles for High-Throughput Phenotyping and Agronomic Research. PLoS ONE 2016, 11, e0159781. [CrossRef]

6. Honkavaara, E.; Saari, H.; Kaivosoja, J.; Pölönen, I.; Hakala, T.; Litkey, P.; Mäkynen, J.; Pesonen, L. Processing and Assessment of Spectrometric, Stereoscopic Imagery Collected Using a Lightweight UAV Spectral Camera for Precision Agriculture. Remote Sens. 2013, 5, 5006-5039. [CrossRef]

7. Candiago, S.; Remondino, F.; De Giglio, M.; Dubbini, M.; Gattelli, M. Evaluating Multispectral Images and Vegetation Indices for Precision Farming Applications from UAV Images. Remote Sens. 2015, 7, 4026-4047. [CrossRef]

8. Csillik, O.; Cherbini, J.; Johnson, R.; Lyons, A.; Kelly, M. Identification of Citrus Trees from Unmanned Aerial Vehicle Imagery Using Convolutional Neural Networks. Drones 2018, 2, 39. [CrossRef]

9. Cano, E.; Horton, R.; Liljegren, C.; Bulanon, D. Comparison of Small Unmanned Aerial Vehicles Performance Using Image Processing. J. Imaging 2017, 3, 4. [CrossRef]

10. Adão, T.; Hruška, J.; Pádua, L.; Bessa, J.; Peres, E.; Morais, R.; Sousa, J. Hyperspectral Imaging: A Review on UAV-Based Sensors, Data Processing and Applications for Agriculture and Forestry. Remote Sens. 2017, 9, 1110. [CrossRef]

11. Matese, A.; Di Gennaro, S. Practical Applications of a Multisensor UAV Platform Based on Multispectral, Thermal and RGB High Resolution Images in Precision Viticulture. Agriculture 2018, 8, 116. [CrossRef]

12. de Castro, A.; Jiménez-Brenes, F.; Torres-Sánchez, J.; Peña, J.; Borra-Serrano, I.; López-Granados, F. 3-D Characterization of Vineyards Using a Novel UAV Imagery-Based OBIA Procedure for Precision Viticulture Applications. Remote Sens. 2018, 10, 584. [CrossRef]

13. Gnädinger, F.; Schmidhalter, U. Digital Counts of Maize Plants by Unmanned Aerial Vehicles (UAVs). Remote Sens. 2017, 9, 544. [CrossRef]

14. Du, M.; Noguchi, N. Monitoring of Wheat Growth Status and Mapping of Wheat Yield's within-Field Spatial Variations Using Color Images Acquired from UAV-camera System. Remote Sens. 2017, 9, 289. [CrossRef]

15. Yue, J.; Yang, G.; Li, C.; Li, Z.; Wang, Y.; Feng, H.; Xu, B. Estimation of Winter Wheat Above-Ground Biomass Using Unmanned Aerial Vehicle-Based Snapshot Hyperspectral Sensor and Crop Height Improved Models. Remote Sens. 2017, 9, 708. [CrossRef]

16. González-Jorge, H.; Martínez-Sánchez, J.; Bueno, M.; Pedor Arias, A. Unmanned Aerial Systems for Civil Applications: A Review. Drones 2017, 1, 2. [CrossRef]

17. Wan, L.; Li, Y.; Cen, H.; Zhu, J.; Yin, W.; Wu, W.; Zhu, H.; Sun, D.; Zhou, W.; He, Y. Combining UAV-Based Vegetation Indices and Image Classification to Estimate Flower Number in Oilseed Rape. Remote Sens. 2018, 10, 1484. [CrossRef]

18. Acorsi, M.G.; das Dores Abati Miranda, F.; Martello, M.; Smaniotto, D.A.; Sartor, L.R. Estimating Biomass of Black Oat Using UAV-Based RGB Imaging. Agronomy 2019, 9, 344. [CrossRef]

19. Vanegas, F.; Bratanov, D.; Powell, K.; Weiss, J.; Gonzalez, F. A Novel Methodology for Improving Plant Pest Surveillance in Vineyards and Crops Using UAV-Based Hyperspectral and Spatial Data. Sensors 2018, 18, 260. [CrossRef]

20. Wu, D.; Sun, D.W. Advanced applications of hyperspectral imaging technology for food quality and safety analysis and assessment: A review-Part I: Fundamentals. Innov. Food Sci. Emerg. Technol. 2013, 19, 1-14. [CrossRef]

21. Boreman, G.D. Classification of imaging spectrometers for remote sensing applications. Opt. Eng. 2005, 44, 013602. [CrossRef]

22. Mogili, U.R.; Deepak, B.B.V.L. Review on Application of Drone Systems in Precision Agriculture. Procedia Comput. Sci. 2018, 133, 502-509. [CrossRef] 
23. Herwitz, S.R.; Johnson, L.F.; Dunagan, S.E.; Higgins, R.G.; Sullivan, D.V.; Zheng, J.; Lobitz, B.M.; Leung, J.G.; Gallmeyer, B.A.; Aoyagi, M.; et al. Imaging from an unmanned aerial vehicle: Agricultural surveillance and decision support. Comput. Electron. Agric. 2004, 44, 49-61. [CrossRef]

24. Maurya, P. Hardware Implementation of a Flight Control System for an Unmanned Aerial Vehicle. Comput. Sci. Eng. 2015. Available online: http://www.cse.iitk.ac.in/users/moona/students/Y2258.pdf (accessed on 8 January 2020).

25. Herwitz, S.R.; Johnson, L.F.; Arvesen, J.C.; Higgins, R.G.; Leung, J.G.; Dunagan, S.E. Precision agriculture as a commercial application for solar-powered unmanned aerial vehicles. In Proceedings of the 1st UAV Conference, Portsmouth, VA, USA, 20-23 May 2002.

26. Pederi, Y.A.; Cheporniuk, H.S. Unmanned Aerial Vehicles and new technological methods of monitoring and crop protection in precision agriculture. In Proceedings of the 2015 IEEE 3rd International Conference Actual Problems of Unmanned Aerial Vehicles Developments, APUAVD 2015-Proceedings, Kyiv, Ukraine, 13-15 October 2015; pp. 298-301.

27. Huang, Y.; Thomson, S.J.; Hoffmann, W.C.; Lan, Y.; Fritz, B.K. Development and prospect of unmanned aerial vehicle technologies for agricultural production management. Int. J. Agric. Biol. Eng. 2013, 6, 1-10.

28. Guidetti, R.; Bodria, L.; Best, S.; Giles, D.K.; Billing, R.C. Deployment and Performance of a UAV for Crop Spraying. In Chemical Engineering Transactions; A publication of AIDIC (The Italian association of chemical engineering): Milano, Italy, 2015; Volume 44.

29. Xue, X.; Lan, Y.; Sun, Z.; Chang, C.; Hoffmann, W.C. Develop an unmanned aerial vehicle based automatic aerial spraying system. Comput. Electron. Agric. 2016, 128, 58-66. [CrossRef]

30. Shilin, W.; Jianli, S.; Xiongkui, H.; Le, S.; Xiaonan, W.; Changling, W.; Zhichong, W.; Yun, L. Performances evaluation of four typical unmanned aerial vehicles used for pesticide application in China. Int. J. Agric. Biol. Eng. 2017, 10, 22-31. [CrossRef]

31. Qin, W.; Xue, X.; Zhang, S.; Gu, W.; Wang, B. Droplet deposition and efficiency of fungicides sprayed with small UAV against wheat powdery mildew. Int. J. Agric. Biol. Eng. 2018, 11, 27-32. [CrossRef]

32. Spoorthi, S.; Shadaksharappa, B.; Suraj, S.; Manasa, V.K. Freyr drone: Pesticide/fertilizers spraying drone-An agricultural approach. In Proceedings of the 2nd International Conference on Computing and Communications Technologies, Maharashtra, India, 15-16 December 2017; pp. 252-255.

33. Kabra, T.S.; Kardile, A.V.; BMane, D.; Bhosale, P.R.; Belekar, A.M. Design, Development \& Optimization of a Quad-Copter for Agricultural Applications. Int. Res. J. Eng. Technol. 2017, 4.

34. Meivel, S.M.; Professor, A.; Maguteeswaran, R.; Gandhiraj, N.B.; Srinivasan, G. Quadcopter UAV Based Fertilizer and Pesticide Spraying System. Int. Acad. Res. J. Eng. Sci. 2016, 1, 8-12.

35. Sohail, S.; Nasim, S.; Khan, N.H. Modeling, controlling and stability of UAV Quad Copter. In Proceedings of the ICIEECT 2017-International Conference on Innovations in Electrical Engineering and Computational Technologies 2017, Karachi, Pakistan, 5-7 April 2017.

36. Qasim, M.; Susanto, E.; Wibowo, A.S. PID control for attitude stabilization of an unmanned aerial vehicle quad-copter. In Proceedings of the 2017 5th International Conference on Instrumentation, Control, and Automation, Yogyakarta, Indonesia, 9-11 August 2017; pp. 109-114.

37. Yallappa, D.; Veerangouda, M.; Maski, D.; Palled, V.; Bheemanna, M. Development and evaluation of drone mounted sprayer for pesticide applications to crops. In Proceedings of the GHTC 2017-IEEE Global Humanitarian Technology Conference, San Jose, CA, USA, 19-22 October 2017; pp. 1-7.

38. Sarghini, F.; De Vivo, A. Interference analysis of an heavy lift multirotor drone flow field and transported spraying system. Chem. Eng. Trans. 2017, 58, 631-636.

39. Berner, B.; Chojnacki, J. Use of Drones in Crop Protection. In Proceedings of the Uniwersytet Przyrodniczy w Lublinie; IX International Scientific Symposium “Farm Machinery and Processes Management in Sustainable Agriculture", Lublin, Poland, 22-24 November 2017; pp. 46-51.

40. Zhang, Y.L.; Lian, Q.; Zhang, W. Design and test of a six-rotor unmanned aerial vehicle (UAV) electrostatic spraying system for crop protection. Int. J. Agric. Biol. Eng. 2017, 10, 68-76.

41. Sarghini, F.; De Vivo, A. Analysis of preliminary design requirements of a heavy lift multirotor drone for agricultural use. Chem. Eng. Trans. 2017, 58, 625-630.

42. Bendig, J.; Bolten, A.; Bareth, G. Introducing A Low-Cost Mini-Uav for Thermal- and Multispectral-Imaging. ISPRS-Int. Arch. Photogramm. Remote Sens. Spat. Inf. Sci. 2012, XXXIX-B1, 345-349. [CrossRef] 
43. Tang, Q.; Zhang, R.R.; Chen, L.P.; Xu, M.; Yi, T.C.; Zhang, B. Droplets movement and deposition of an eight-rotor agricultural UAV in downwash flow field. Int. J. Agric. Biol. Eng. 2017, 10, 47-56.

44. Shah, S.S.H. Development of UAV Octocopter Based on Pesticides Spraying System. Univ. Wah J. Sci. Technol. 2018, 2, 13-17.

45. Yemle, S.; Durgude, Y.; Kondhalkar, G.; Pol, K. Design \& Analysis of Multi-Frame for Octo \& Quad Copter Drones. Int. Res. J. Eng. Technol.(IRJET) 2019, 6.

46. Flethes, S.G.; Suárez, A.; Carlos, G.; Placer, C. Cálculo y selección de sistema de propulsión para mini UAV de apoyo a pequeñas unidades de Infantería de Marina. Available online: http://calderon.cud.uvigo.es/ xmlui/handle/123456789/50 (accessed on 8 January 2020).

47. Iqbal, U.; Irtiza, S.; Shah, A.; Jamil, M.; Gillani, S.O.; Ayaz, Y. Selection Of Unmanned Aerial System (Uas) For Disaster Relief Operations: A Comparison. Sci. Int. 2015, 27, 3199-3203.

48. Skrzypietz, T. Unmanned Aircraft Systems for Civilian Missions; Brandenburgisches Institut für Gesellschaft und Sicherheit (BIGS): Potsdam, Germany, 2012.

49. Jaeger, M.; Adair, D. Conceptual design of a high-endurance hybrid electric unmanned aerial vehicle. Mater. Today Proc. 2017, 4, 4458-4468. [CrossRef]

50. Glassock, R.R.; Hung, J.Y.; Gonzalez, L.F.; Walker, R.A. Multimodal hybrid powerplant for unmanned aerial systems (UAS) Robotics. In Proceedings of the Twenty-Fourth Bristol International Unmanned Air Vehicle Systems Conference, Bristol, UK, 30 March-1 April 2009.

51. Hassanalian, M.; Radmanesh, M.; Sedaghat, A. Increasing flight endurance of MAVs using multiple quantum well solar cells. Int. J. Aeronaut. Space Sci. 2014, 15, 212-217. [CrossRef]

52. Swieringa, K.A.; Hanson, C.B.; Richardson, J.R.; White, J.D.; Hasan, Z.; Qian, E.; Girard, A. Autonomous battery swapping system for small-scale helicopters. In Proceedings of the IEEE International Conference on Robotics and Automation, Anchorage, Alaska, 3-8 May 2010; pp. 3335-3340.

53. Achtelik, M.C.; Stumpf, J.; Gurdan, D.; Doth, K.-M. Design of a flexible high performance quadcopter platform breaking the MAV endurance record with laser power beaming. In Proceedings of the 2011 IEEE/RSJ International Conference on Intelligent Robots and Systems, San Francisco, CA, USA, 25-30 September 2011; pp. 5166-5172.

54. Muttin, F. Umbilical deployment modeling for tethered UAV detecting oil pollution from ship. Appl. Ocean Res. 2011, 33, 332-343. [CrossRef]

55. José Caparrós Mancera, J.; José Vivas Fernández, F.; Manuel Andujar Marquez, J. Optimized Balance of Plant for a medium-size PEM electrolyzer. Design, Modelling and Control. In Proceedings of the EUROSIM 2019 Abstract Volume, 10th EUROSIM Congress, La Rioja, Logroño, Spain, 1-5 July 2019. [CrossRef]

56. Rajendran, P.; Smith, H. Review of Solar and Battery Power System Development for Solar-Powered Electric Unmanned Aerial Vehicles. Adv. Mater. Res. 2015, 1125, 641-647. [CrossRef]

57. Shiau, J.K.; Ma, D.M.; Yang, P.Y.; Wang, G.F.; Gong, J.H. Design of a solar power management system for an experimental UAV. IEEE Trans. Aerosp. Electron. Syst. 2009, 45, 1350. [CrossRef]

58. Brelje, B.J.; Martins, J.R.R.A. Electric, hybrid, and turboelectric fixed-wing aircraft: A review of concepts, models, and design approaches. Prog. Aerosp. Sci. 2019, 104, 1-19. [CrossRef]

59. Donateo, T.; Lucia De Pascalis, C.; Ficarella, A. Synergy Effects in Electric and Hybrid Electric Aircraft. Aerospace 2019, 6, 32. [CrossRef]

60. Lei, T.; Yang, Z.; Lin, Z.; Zhang, X. State of art on energy management strategy for hybrid-powered unmanned aerial vehicle. Chin. J. Aeronaut. 2019, 32, 1488-1503. [CrossRef]

61. Boukoberine, M.N.; Zhou, Z.; Benbouzid, M. A critical review on unmanned aerial vehicles power supply and energy management: Solutions, strategies, and prospects. Appl. Energy 2019, 255, 113823. [CrossRef]

62. Dutczak, J. Liquefied and chemical hydrogen storage in contemporary small drones' fuel cell propulsion systems. In Proceedings of the IOP Conference Series: Materials Science and Engineering, Nanjing, China, 17-19 August 2018; Volume 421.

63. Herrera, G.J.; Dechant, J.A.; Green, E.K. Technology Trends in Small Unmanned Aircraft Systems (sUAS) and Counter-UAS: A Five-Year Outlook; Institute for Defense Analyses Alexandria: Alexandria, VA, USA, 2017.

64. Babayomi, O.O.; Makarfi, A.U. Energy Efficiency in Unmanned Aircraft Systems: A Review. In Proceedings of the 2019 IEEE PES/IAS PowerAfrica, Abuja, Nigeria, 20-23 August 2019; pp. 569-574.

65. Gramatikov, P. Electric Motor-Generators for Unmanned Aerial Vehicles; Bulgarian Academy of Sciences. Space Research and Technology Institute: Sofia, Bulgaria, 2017; Volume 29. 
66. Griffis, C.; Wilson, T.; Schneider, J.; Pierpont, P. Unmanned Aircraft System Propulsion Systems Technology Survey; Air Traffic Organization. NextGen \& Operations Planning Office of Research and Technology Development: Washington, DC, USA. Available online: https:/commons.erau.edu/publication/72.DOT/FAA/AR-09/11 (accessed on 8 January 2020).

67. Tecnolivo-Programa INTERREG V-A España-Portugal (POCTEP 2014-2020). Available online: https: //www.tecnolivo.eu/en/ (accessed on 2 January 2020).

68. Isorna, F.; Fernandez Barranco, A.; Bogeat, J.A.; Segura, F.; Andujar, J.M. (PDF) Use of unmanned fuel cell ground vehicles (UGVs) for precision agricul-ture (TecnOlivo Project). In Proceedings of theVII Symposium on Hydrogen, Fuel Cells and Advanced Batteries (HYCELTEC 2019), Barcelona, España, 1-3 July 2019. Available online: https://www.researchgate.net/publication/335060764_Use_of_unmanned_fuel_ cell_ground_vehicles_UGVs_for_precision_agricul-_ture_TecnOlivo_Project (accessed on 25 January 2020).

69. Ponce, J.M.; Aquino, A.; Millan, B.; Andujar, J.M. Automatic Counting and Individual Size and Mass Estimation of Olive-Fruits Through Computer Vision Techniques. IEEE Access 2019, 7, 59451-59465. [CrossRef]

70. Ponce, J.M.; Aquino, A.; Andujar, J.M. Olive-Fruit Variety Classification by Means of Image Processing and Convolutional Neural Networks. IEEE Access 2019, 7, 147629-147641. [CrossRef]

71. Adamski, M. Analysis of propulsion systems of unmanned aerial vehicles. J. Mar. Eng. Technol. 2018, 16, 291-297. [CrossRef]

72. Gabriel, D.L.; Meyer, J.; Du Plessis, F. Brushless DC motor characterisation and selection for a fixed wing UAV. In Proceedings of the IEEE AFRICON Conference, Livingstone, Zambia, 13-15 September 2011.

73. Hughes, A.; Drury, B. Electric Motors and Drives: Fundamentals, Types and Applications; Newnes: Waltham, MA, USA; ISBN 978-0-08-098332-5.

74. MGM COMPRO, Ing. G. Dvorský. HBC - SERIES V7 Programmable brushless controllers for industry using Operating Manual - firmware version 3.8 or higher. Republic, C. Hsbc - Series V7. 1-54. Available online: www.mgm-compro.com (accessed on 8 January 2020).

75. Farmann, A.; Waag, W.; Marongiu, A.; Sauer, D.U. Critical review of on-board capacity estimation techniques for lithium-ion batteries in electric and hybrid electric vehicles. J. Power Sources 2015, 281, 114-130. [CrossRef]

76. Yanping, Z.; Zhenguo, Y. Model No: glpa875170 16000 15c 3.7v; SHENZHEN GREPOW BATTERY CO., LTD: Shenzhen, China, 2013. Available online: http:www.grepow.com (accessed on 8 January 2020).

77. Traub, L.W. Range and endurance estimates for battery-powered aircraft. J. Aircr. 2011, 48, $703-707$. [CrossRef]

78. Avanzini, G.; Giulietti, F. Maximum range for battery-powered aircraft. J. Aircr. 2013, 50, 304-307. [CrossRef]

79. Tu, W.; Bai, Z.; Deng, Z.; Zhang, H.; Tang, H. In-situ synthesized Si@C materials for the lithium ion battery: A mini review. Nanomaterials 2019, 9, 432. [CrossRef] [PubMed]

80. Levchenko, I.; Bazaka, K.; Belmonte, T.; Keidar, M.; Xu, S. Advanced Materials for Next-Generation Spacecraft. Adv. Mater. 2018, 9, 432. [CrossRef] [PubMed]

81. Mauger, A.; Julien, C.M. Nanoscience supporting the research on the negative electrodes of Li-ion batteries. Nanomaterials 2015, 5, 2279-2301. [CrossRef] [PubMed]

82. Energus Power Solutions Ltd. Tiny BMS User Manual. 30 July 2018, pp. 1-148. Available online: https://www.energusps.com/ (accessed on 8 January 2020).

83. Arbin. BT-ML; Arbin Instrument: College Station, TX, USA, December 2015.

84. Arbin. Arbin Instruments User's Manual; Arbin Instrument: College Station, TX, USA, 2013.

85. Chung, P.H.; Ma, D.M.; Shiau, J.K. Design, manufacturing, and flight testing of an experimental flying wing UAV. Appl. Sci. 2019, 9, 3043. [CrossRef]

86. Zhai, R.; Zhou, Z.; Zhang, W.; Sang, S.; Li, P. Control and navigation system for a fixed-wing unmanned aerial vehicle. AIP Adv. 2014, 4. [CrossRef]

87. Grant, P.R. AER1216: Fundamentals of UAVs performance; (CARRE) Centre for aerial robotics research and education, NSERC, CRSNG: Canada, 2016.

88. Lopez, E.; Monteiro, J.; Carrasco, P.; Saenz, J.; Pinto, N.; Blazquez, G. Development, implementation and evaluation of a wireless sensor network and a web-based platform for the monitoring and management of a microgrid with renewable energy sources. In Proceedings of the SEST 2019-2nd International Conference on Smart Energy Systems and Technologies, Porto, Portugal, 9-11 September 2019. 
89. Bradley, T.H.; Moffitt, B.A.; Fuller, T.F.; Mavris, D.N.; Parekh, D.E. Comparison of design methods for fuel-cell-powered unmanned aerial vehicles. J. Aircr. 2012, 46, 1945-1956. [CrossRef]

90. Bradley, T.H.; Moffitt, B.A.; Thomas, R.W.; Mavris, D.; Parekh, D.E. Test Results for a Fuel Cell-Powered Demonstration Aircraft; SAE Technical Papers; SAE International: Warrendale, TX, USA, 2006.

91. Chacón, E.; Martínez, G.; Anchuelo, C.; Cuevas, R.; Chacón, E.; Martínez, G.; Anchuelo, C.; Cuevas, R. Unmanned Aerial Vehicle Driven by Fuel Cell Technology, AVIZOR. In Proceedings of the 18th World Hydrogen Energy Conference 2010 - WHEC 2010; Forschungszentrum Jülich GmbH, Zentralbibliothek Verlag: Jülich, Germany, 2010; Volume 78, ISBN 978-3-89336-655-2.

(C) 2020 by the authors. Licensee MDPI, Basel, Switzerland. This article is an open access article distributed under the terms and conditions of the Creative Commons Attribution (CC BY) license (http://creativecommons.org/licenses/by/4.0/). 